\title{
RESEARCH REVIEW OF POTENTIAL SAFETY EFFECTS OF ELECTRONIC BILLBOARDS ON DRIVER ATTENTION AND DISTRACTION
}

\section{FINAL REPORT}

\author{
September 11, 2001
}

\author{
Submitted to: \\ Office of Real Estate Services \\ and \\ Safety Core Business Unit \\ Federal Highway Administration
}

From:

Human Centered Systems Team

Office of Safety Research and Development

Federal Highway Administration 
Technical Report Documentation Page

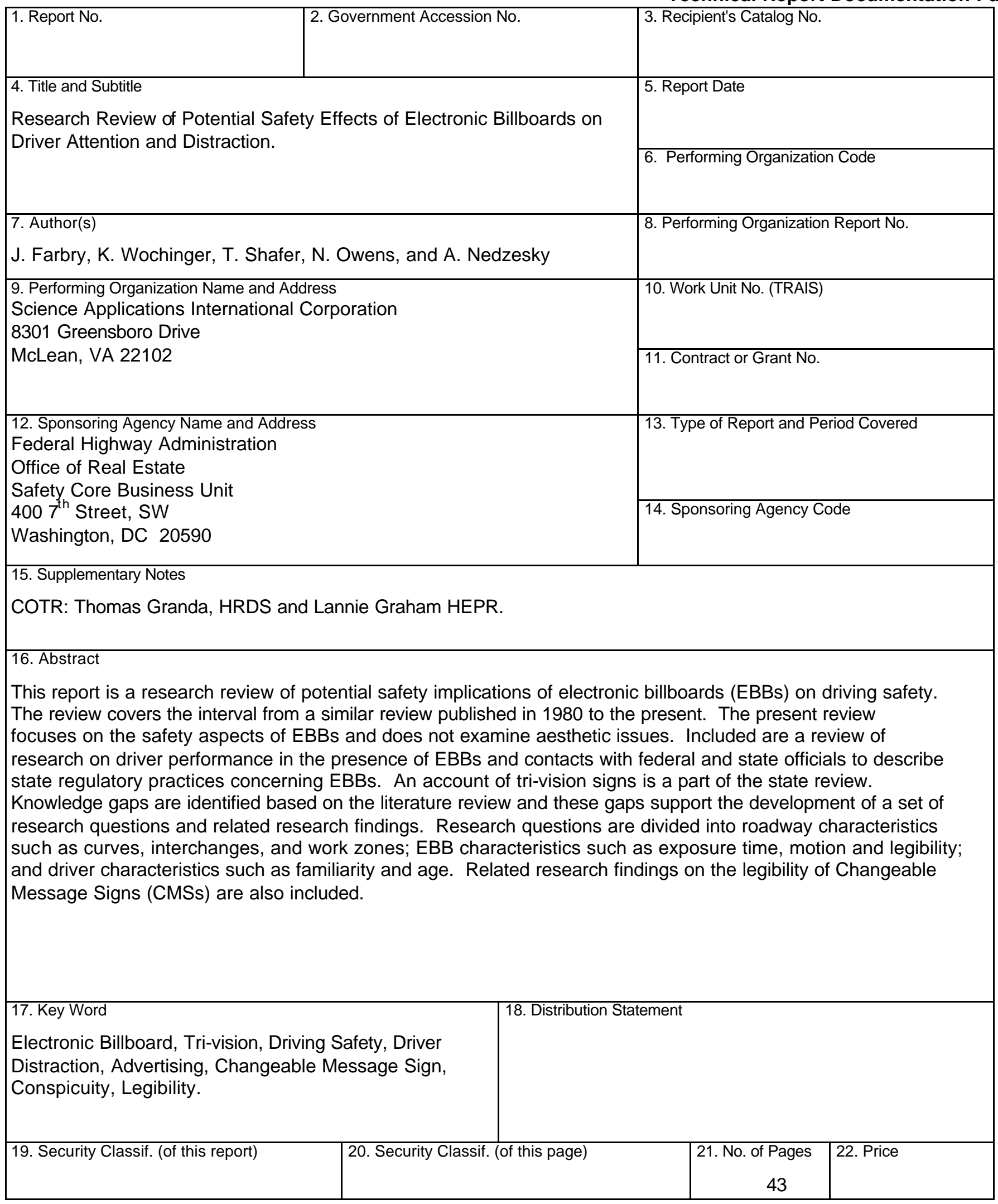

Form DOT F 1700.7 (8-72) Reproduction of completed page authorized 


\section{Notice}

This document is disseminated under the sponsorship of the Department of

Transportation in the interest of information exchange. The United States

Government assumes no liability for its contents or use thereof. This report does not constitute a standard, specification, or regulation.

The United States Government does not endorse products or manufacturers. Trade and manufacturers' names appear in this report only because they are considered essential to the object of the document. 


\section{Table of Contents}

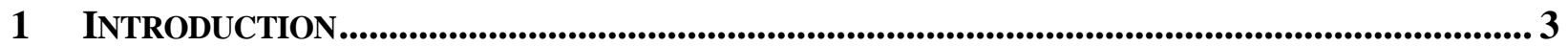

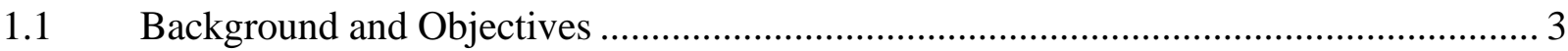

$1.2 \quad$ Structure of the Report ......................................................................................... 3

2 LITERATURE REVIEW ....................................................................................................... 4

$2.1 \quad$ Types of Electronic Billboards ................................................................................. 4

2.2 State Regulations and Policies on Electronic Billboards ..............................................5

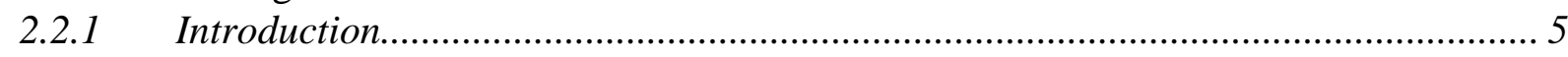

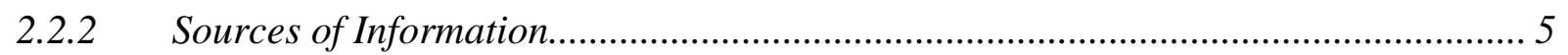

2.2.3 State Regulations and Practices .............................................................................. 6

2.2.4 National Alliance of Highway Beautification Agencies.............................................. 7

2.2.5 State Outdoor Advertising Regulations ……………......................................... 8

2.2.6 Concerns about Electronic Billboards..................................................................... 8

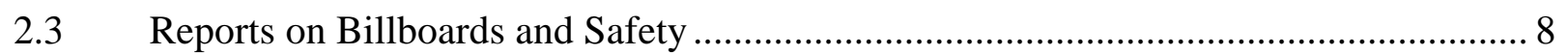

2.3.1 The Wachtel and Netherton Report................................................................... 8

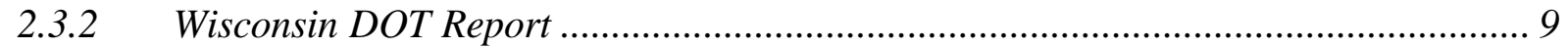

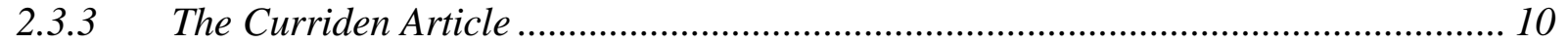

$2.4 \quad$ Potential Safety Factors ………………………............................................. 10

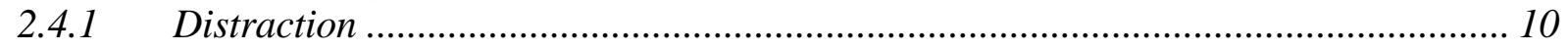

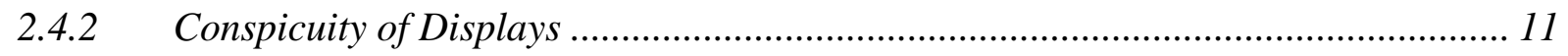

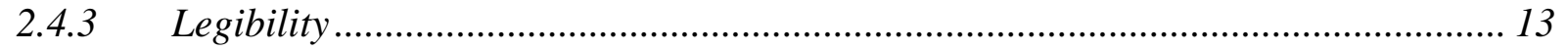

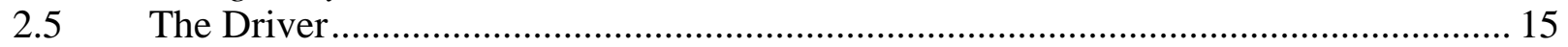

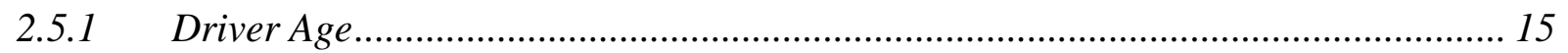

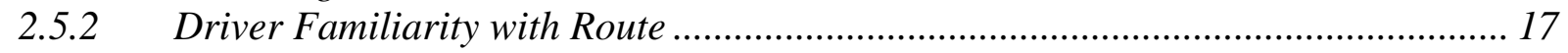

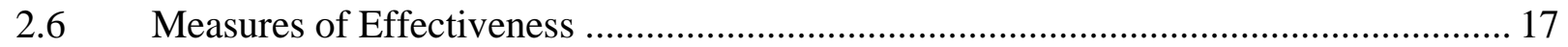

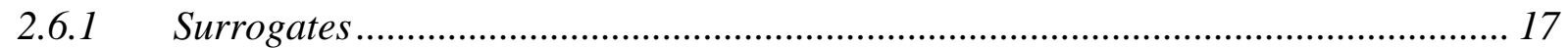

2.6.2 Current Measurement of Distraction..................................................................... 18

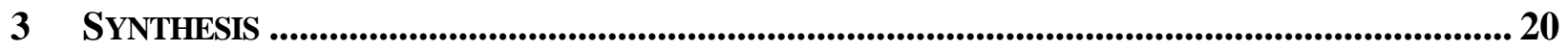

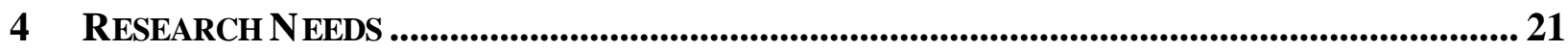

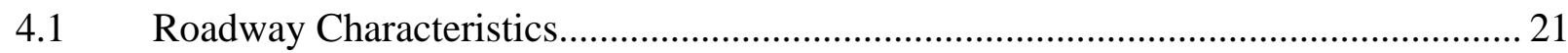

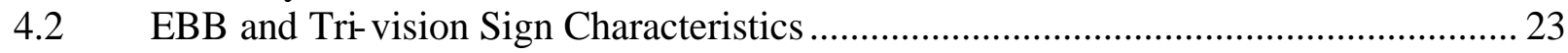

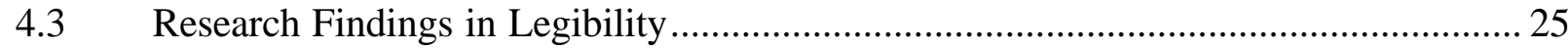

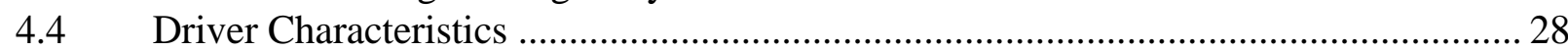

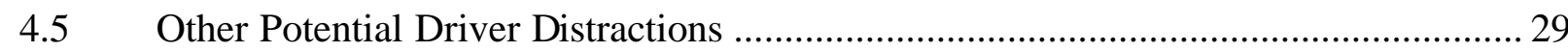

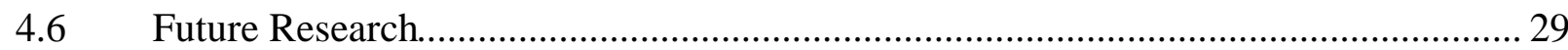

4.7 Research Methods ........................................................................................ 30

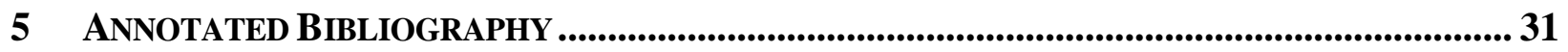

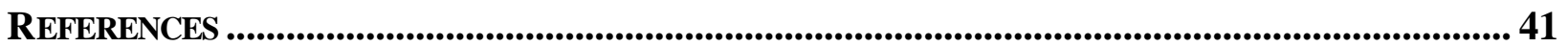




\section{LIST OF TABLES}

Table 1. Timing Boundaries of Several Tri-Vision Billboard Policies............................................. 7

Table 2. Recommended Minimum Luminance Values (cd/m2) for CMS Visibility........................... 26 


\section{EXECUTIVE SUMMARY}

Advances in display technology and decreases in cost have created interest to expand the deployment of high resolution and dynamic imaging. The introduction of such technology to billboards, where static displays of advertising have been the standard, raises questions on the effects that electronic billboards (EBBs) may have on drivers' attention.

The Office of Real Estate Services and the Safety Core Business Unit in the Federal Highway Administration (FHWA) requested the FHWA Office of Safety, Research and Development to review literature related to the safety implications of EBBs, present findings, and recommend a research plan to address knowledge gaps. This project follows earlier work sponsored by the FHWA in 1980 and compliments driver distraction studies relative to in-vehicle displays currently underway.

Based on conversations with government staff and examination of state regulations, the literature review summarized state billboard regulations and policies relevant to EBBs and tri-vision signs. The review then encompassed billboard-related crash analyses and potential safety factors such as distraction, conspicuity, and legibility. Due to the limited amount of research regarding external distraction in drivers, internal distractions, such as in-vehicle information systems and cellular telephones, were used as surrogates when investigating how potential distractions affect the driver.

As the literature review identified and summarized potential safety effects of EBBs and tri-vision signs, many questions became evident. The synthesis section organized these questions into knowledge gaps. The identified knowledge gaps have been categorized into the areas of roadway geometry characteristics, EBB and tri-vision sign characteristics, and driver characteristics.

Since this effort was purely a review of existing literature, no formal research was completed; the purpose of the remainder of the research review was to build upon the identified knowledge gaps. Each of the gaps was analyzed and preliminary research plans were proposed. Included in each plan are associated goals and proposed research questions. When possible, relevant research findings in which the research questions were based upon were identified.

Roadway characteristics that were recognized for future research in the knowledge gap section include horizontal and vertical curves, intersections, work zones, and EBB billboard spacing. EBBs and tri-vision sign characteristics and their proposed research questions are related to an EBB's message content and comprehensibility, exposure time, motion, and sign maintenance. Finally, research questions related to driver characteristics are directed to age and route familiarity. 


\section{INTRODUCTION}

\subsection{Background and Objectives}

Advances in outdoor display technology, and decreases in cost, support an interest in expanding deployment of high resolution and dynamic imaging in outdoor advertising. This raises questions on the effects that electronic billboards (EBBs) and other dynamic signs such as trivision signs may have on driver distraction. The purpose of this report is to present a review of the literature on the safety implications of electronic billboards, to identify knowledge gaps in the findings of the review, and to develop a research plan to address the knowledge gaps.

The Office of Real Estate Services (ORES) and the Safety Core Business Unit in the Federal Highway Administration (FHWA) requested the FHWA Office of Safety, Research and Development to review literature related to safety implications of EBBs, present findings, and recommend a research plan to address knowledge gaps. The scope of this review was limited to safety issues. This project follows an earlier work sponsored by the FHWA in 1980 and complements studies of in-vehicle driver distraction currently underway.

The general approach in the present review was to identify information about potential safety implications of EBBs. Factual data regarding billboard safety were sought through a review of existing research literature and information obtained from government staff. Because driver distraction is of interest in other areas of research, such as cellular telephone use and in-vehicle visual information equipment, the present report examines these areas for possible crossfertilization results. The report concludes with a set of research questions and research findings that are directed to the safe design of dynamic billboards.

\subsection{Structure of the Report}

The Literature Review in Section 2 defines EBBs and tri-vision signs, provides a survey of state practices, and reviews research on EBBs and related distraction research. The Synthesis in Section 3 provides a list of knowledge gaps that were identified in the literature review. Section 4 proposes research in the format of research questions and presents related research findings that are directed to understanding driver behavior in the presence of EBBs and tri-vision signs. The report also contains an annotated bibliography and appendices. 


\section{LITERATURE REVIEW}

The literature review researched two types of information to understand the safety implications of electronic billboards. One research effort examined current state practices in the regulation of EBBs to determine, for example, the features of those displays at which the regulation is directed and the consistency of regulation among the states. The other type of information was derived mostly from research studies that had the objective of understanding driver behavior in the presence of electronic billboards and/or tri-vision signs. Information of the latter type can provide a source for informed state planning.

The review begins with a description of electronic billboards, tri-vision signs, and a discussion of the relationship of these two display types to changeable message signs used for transmitting roadway status information. The next section describes the results of the review of current state practices on billboard regulation and this is followed by the review of research studies.

\subsection{Types of Electronic Billboards}

Technology has advanced sufficiently for billboards to provide dynamic and realistic views much like color television. The advanced EBB has the capability to present multiple views and objects that have realistic motion. In contrast, tri-vision signs provide one of three views with rotating cylinders and generate mechanical motion or movement. Since both the EBB and trivision sign incorporate components that display motion, some of the issues associated with EBBs are also associated with tri-vision signs. These two types will be compared in functional terms.

For the purpose of the present report, the definition of an EBB is a programmable display that has the capability to present a large amount of text and/or symbolic imagery. Some EBBs present images in realistic motion and in a large variety of colors. The tri-vision sign is defined as a display device capable of presenting three separate images sequentially by rotating triangular cylinders. Appendix A shows examples of EBBs and a tri-vision sign.

The EBB consists of several visual characteristics. EBBs present high-resolution color images, complex visual arrangements, rich variation in color, and a vast amount of images. Operational characteristics include electric power and remote control though a computer terminal. The EBB screen display elements are typically arranged in a matrix. The shape of the EBB is usually rectangular, but irregular shapes are possible. An example is the EBB on the NASDAQ Marketsite's Tower in New York City's Times Square. This EEB wraps around the corner of the building. ${ }^{(1)}$ The NASDAQ video screen is eight stories high and covers 10,736 square ft with light-emitting diodes (LEDs).

The EBB can vary in complexity. Whereas some EBBs display motion, fine detail, and a rich variety of color, other EBBs provide a simpler image. This image is often composed of a short sequence of words in which each letter is defined by a small number of matrix elements such as a $4 \times 6$ matrix or a 5x7 matrix. The elements are typically light emitting (i.e., LEDs or incandescent) and presented against a dark background. This simpler version of the EBB shares features of the display used by governmental agencies for presenting information to drivers. This display is referred to as a changeable message sign (CMS) in this paper. The CMS typically employs a matrix technology to provide variable messages displays. Other equivalent terms currently used for this sign are variable message sign (VMS) and, to a lesser extent, dynamic message sign (DMS). The permanent CMS is found mounted above the roadway whereas a portable CMS is usually mobile and is located on the shoulder of the roadway. 
Whereas the EBB can display a vast number of images, the tri-vision sign is more limited. The typical tri-vision sign is composed of a series of vertical or horizontal cylinders each of which has a triangular cross section. Each partial rotation of the group of triangular cylinders produces a different image. A single tri-vision sign typically displays, at any given time, one of three images. Although the final composite image does not provide motion, there is still movement due to the transition from one image to another as the cylinders rotate. This movement can act as an attention-getting feature that attracts the driver's attention to the display. One such feature present during the rotation is the partial viewing of two images in transition, where one image advances as the other retreats. Another feature is the change in reflective qualities among the different sides of the triangular cylinders during the transition.

\subsection{State Regulations and Policies on Electronic Billboards}

\subsubsection{Introduction}

This section of the literature review pertains to the regulation of EBBs across the United States. A review of existing states' regulations and policies is presented first since it is believed that this will provide the reader with an understanding of how EBBs fit into various states' outdoor advertising policies. Each state's regulations generally derive from the 1965 Highway Beautification Act (HBA). A detailed history and overview of the federal outdoor advertising control program, which includes the HBA, can be found on the FHWA's ORES web site: http://www.fhwa.dot.gov/realestate/oacprog.htm. A review of state outdoor advertising regulations revealed that common billboard guidelines governing EBBs and tri-vision signs do not exist. While states generally have consistent regulations governing static billboards, regulations covering EBBs and tri-vision signs vary widely. Implementation practices differ significantly from state to state. A broad spectrum of regulations exists, ranging from lenient control to the prohibition of outdoor advertising.

\subsubsection{Sources of Information}

Federal and state Department of Transportation (DOT) personnel provided information regarding state regulations and policies. The information pertained to whether states regulate EBBs, and if so, in what manner. The sources of information are described briefly as follows:

- $\quad$ State Outdoor Advertising Regulations. Efforts were made to obtain the most current billboard regulations nationwide. These regulations were collected from various sources, such as the state DOT directly, a state's website, or from the National Alliance of Highway Beautification Agencies' (NAHBA) website. Overall, regulations were obtained from 44 states.

- $\quad$ Personal Communication. In addition to obtaining state documents, the researchers contacted states and FHWA division offices. Since a supporting contractor was to be directly contacting state DOTs, an introductory e-mail message was sent from FHWA Headquarters to each Division Office to notify the FHWA Division Office and the state DOTs of the contractor's role. The FHWA contractor contacted state personnel who were knowledgeable of their state's billboard regulations. The telephone calls were of an unstructured nature, and their purpose was to determine if local constituents had submitted comments or complaints about EBBs, and if research had been conducted on EBBs in the state. 
FHWA Division Offices. Nine FHWA Division Offices were contacted. FHWA's ORES recommended some of the selected Division Offices and others were selected randomly.

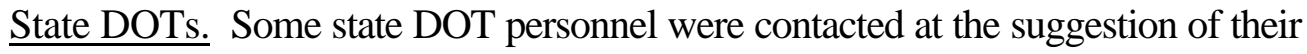
local FHWA Division Office while other states were selected randomly. Ten state DOTs were contacted by telephone.

National Alliance of Highway Beautification Agencies (NAHBA). In the early 1990s, a group of individuals responsible for directing or managing their state's outdoor advertising program formed the NAHBA. The Alliance meets regularly to discuss new developments in technology, upcoming legislation, and ways to improve or stream-line regulation of outdoor advertising, junkyards, landscaping, and visitor centers. Additionally, NAHBA maintains a website that contains outdoor advertising regulations of numerous states and the federal government.

A NAHBA meeting was held in Washington, D.C., in late January 2001. Two members of the research team and their FHWA contracting officer technical representative met with NAHBA members after the formal meeting had ended. Representatives of Florida, Kentucky, Missouri, Oklahoma, and Utah were present. The meeting served a purpose similar to the telephone calls, except that it allowed a more interactive conversation in more detail.

NAHBA provided the responses from an informal email questionnaire pertaining to EBBs and a tri-vision sign survey to the research team. These are presented in a subsequent section of this report.

\subsubsection{State Regulations and Practices}

In a July 1996 memorandum to FHWA Regional Administrators, the ORES provided additional interpretation of advertising technology to the individual states regarding off-premise changeable message signs. An off-premise sign is a sign that disseminates information that does not directly relate to the use of the property on which the sign is located. ("Changeable message signs are acceptable for off-premise signs regardless of the type of technology used, if the interpretation of the State/Federal agreement allows such signs," page 1, paragraph 2, sentence 4 of the memorandum).

In a July 1998 memorandum, the ORES reaffirmed their policy that off-premise signs using animated or scrolling displays that are dependent on flashing, intermittent, or moving lights were not conforming signs. This decision was made after careful review of a videotape showing the full-motion EBB erected in Scottsbluff, Nebraska. It was concluded that such signs raise "significant highway safety questions because of the potential to be extremely bright, rapidly changing, and distracting to motorists," (page 1, paragraph 4, sentence 1 of the memorandum).

A majority of states have a policy regarding the lighting of billboards, and through this policy, states regulate EBBs. While common themes are present in most lighting regulations, each state's laws have unique wording. As an example, the Arkansas State Highway and Transportation Department's Outdoor Advertising Policy, ${ }^{(2)}$ Regulations for Control of Outdoor Advertising on Arkansas Highways, as authorized by Arkansas Act 640 of 1967 and Highway Commission Minute Order No. 77-6, section III, subsection D, Lighting states: 
A. Lighting Signs may be illuminated, subject to the following restrictions:

1. Signs, which contain, include, or are illuminated by any flashing, intermittent, or moving light or lights are prohibited, except those giving public service information such as time, date, temperature, weather, or similar information.

2. Signs which are not effectively shielded as to prevent beams or rays of light from being directed at any portion of the traveled ways of the Interstate or Primary highways and which are of such intensity or brilliance as to cause glare or to impair the vision of the driver of any motor vehicle, or which otherwise interferes with any driver's operation of a motor vehicle are prohibited.

3. No sign shall be so illuminated that it interferes with the effectiveness of, or obscures an official traffic sign, device, or signal.

\subsubsection{National Alliance of Highway Beautification Agencies}

Tri-vision Sign Survey. A 1999 survey sponsored by and presented at the annual NAHBA conference reviewed the tri-vision sign advertising regulations of every state and Washington, DC. The following results show that a majority of states are addressing current advertising technologies in their outdoor advertising regulations. At the time of the survey:

- Nine states had specific regulations governing signs,

- Nine states had regulations on tri-vision signs that were either being drafted or in pending legislation,

- Fifteen states had regulations regarding moving parts and/or lights,

- Nine state had no regulations on tri-vision sign, and

- Six states as well as Washington, DC, prohibited tri-vision signs.

Table 1 provides a summary of tri-vision sign exposure dwell times and transition times that were presented in the 1999 NAHBA survey.

Table 1. Timing Boundaries of Several Tri-Vision Sign Policies.

\begin{tabular}{lccc}
\hline Timing Boundaries & Average & Maximum & Minimum \\
\hline Minimum Exposure Dwell Time (sec) $^{1}$ & 7.32 & 10 & 4 \\
Maximum Transition Twirl Time (sec) $^{2}$ & 2.16 & 4 & 1 \\
\hline
\end{tabular}

Source: NAHBA 1999 Conference.

${ }^{1}$ Minimum Exposure Dwell Time: For billboards that change messages, (e.g., tri-vision sign or CMSs), the exposure time can be defined as the minimum amount of time, in seconds, that a message must be shown. Some minimum exposure times have been derived from analytical calculations (based on speed limit and the number of faces of a billboard that can be seen) while other minimum exposure times have come in the form of recommendations from outdoor advertising suppliers or have been based upon engineering judgment.

${ }^{2}$ Maximum Transition Twirl Time: The transition time is the amount of time, in seconds, that is required for a billboard (such as and EBB or tri-vision sign) to automatically change messages. Many states have set a maximum transition time for this change. The maximum was originally determined by taking into account the mechanical constraints of older tri-vision signs and attempting to limit the amount of visual distraction caused by a sign's transition. Due to advances in technology, transitions executed by a full-motion video billboard are virtually instantaneous.

Electronic Sign Data. In early February 2001, NAHBA asked its membership to answer four questions regarding EBBs. One question relevant to this research is: "Do you have a definition 
of an electronic sign?" Of the 20 responses that were received, five states had a definition, 14 did not have a definition, and one state was in the process of rewriting its definition.

\subsubsection{State Outdoor Advertising Regulations}

A review of statutes was conducted to identify state prohibitions on specific characteristics of signs. This review is presented in Appendices B and C. The results indicate, in part, that of 42 states:

- Thirty-six states had prohibitions on signs with red, flashing, intermittent, or moving lights,

- Twenty-nine states prohibited signs that were so illuminated as to obscure or interfere with traffic control devices, and

- Twenty-nine states prohibited signs located on interstate or primary highway outside of the zoning authority of incorporated cities within $500 \mathrm{ft}$ of an interchange or intersection at grade or safety roadside area.

Additional information on other sign characteristics includes insufficient shielding of light, timing limits, and sign location relative to traffic control devices.

\subsubsection{Concerns about Electronic Billboards}

Numerous states have attempted to identify a relationship between EBBs and safety by using traffic conditions as a surrogate measure. The states of Nevada, Utah, Texas, New York, New Hampshire, and Massachusetts reported no evidence of increased traffic safety problems after the installation of electronic information displays in their city centers and along their highways. Additionally, five state DOT personnel were asked if a crash relationship with EBBs existed in their states; the responses were that a relationship between crashes and EBBs was not identifiable. However, one belief is that EBBs are typically on congested roadways where drivers have time to look at the sign, so it is difficult to determine if the EBBs cause crashes, let alone traffic congestion.

\subsection{Reports on Billboards and Safety}

Determining the effect of roadway commercial advertising billboards on safety is a difficult endeavor for several theoretical and methodological reasons. First, crash frequency is often used as a measure of safety, yet crashes occur relatively infrequently, so changes in frequency may be subtle and are not easily attributed to particular factors. In addition, distraction effects may interact with other factors, such as weather. Furthermore, crash reporting procedures differ across jurisdictions and may not refer to billboard distraction as a factor in the crash. Additionally, drivers may be unlikely to identify distraction as the cause of a crash for liability reasons. Regardless of these difficulties, researchers have examined the effects of billboards on safety. The results are mixed and inconclusive, as shown below.

\subsubsection{The Wachtel and Netherton Report}

The safety and aesthetics of commercial electronic variable message signing were reviewed by the FHWA in $1980^{(3)}$ and are summarized below. Part of that effort included a review of published studies on the safety effect of roadside advertising signs, including several field and 
laboratory studies from 1951 to 1978 on non-electronic advertising billboards, and one analysis in 1976 of an electronic advertising sign in Boston.

The Minnesota Department of Highways concluded from a field study in 1951 that an increase in commercial billboards would result in an increased crash rate. A 1951 field study conducted by Iowa State College concluded that more crashes caused by driver inattention occurred on road segments that contained billboards. The Michigan State Highway Department in 1952 found that advertising signs did not correlate with the roadway's crash experience, except for illuminated (neon) signs, which did correlate with an increased crash rate. A 1961 study of California Route 40 concluded that road segments with billboards experienced significantly more crashes than segments without billboards. A 1967 field study compared the crash history of three locations in Chicago before and after the installation of three illuminated, commercial changeable message signs. Crash rates did not change at two of the sign locations, but the third sign location showed an increase of crashes. The third sign had alternating lights, showed several advertising messages, and was illuminated by bright white lights. The rapid increase in crashes led state highway officials to request that blue lights replace the white lights. ${ }^{(3)}$

The Tele-Spot sign in Boston was an off-premise commercial electronic sign. The sign was visible from the Central Artery in the midst of complex on- and off-ramps, regulatory signs, and guide signing. The Massachusetts Outdoor Advertising Board conducted an analysis of traffic crashes three years before and two and a quarter years after sign installation. The analysis showed an overall reduction in the Average Daily Traffic (ADT) and crashes along the expressway, but on the areas of the expressway from where the Tele-Spot was visible, the crash reduction was 10 percent less than the overall reduction. The Board regarded the 10-percent difference as an indication that the Tele-Spot sign was a distraction and a safety risk, and consequently revoked the license for the sign. ${ }^{(3)}$

\subsubsection{Wisconsin DOT Report}

The Wisconsin DOT examined the crash rates on Interstate 94 eastbound and westbound adjacent to the Milwaukee County Stadium ${ }^{(4)}$. The analysis compared the crash rates three years before and three years after the installation of a variable message advertising sign. The sign, installed April 13, 1984, displayed sporting scores and advertisements, and changed images an average of 12 frames per minute. The purpose of the comparison was to assess whether the presence of the sign correlated with a change in the crash history of I-94. To determine crash rate, the Wisconsin DOT inventoried crashes that occurred on the segment on I-94 from where the sign was visible, categorized them into side-swipe and rear-end crashes, and determined the ADT from an automatic traffic recorder. The crash rate was derived from the equation:

$$
\text { crash rate per million vehicle miles }=\text { crash frequency/(length of segment) } * \text { ADT } * 10^{6} \text { ) }
$$

Eastbound Segment. The crash rate for the three years before installation was 3.12 crashes per million vehicle miles traveled (VMT). The three-year crash rate after installation was 4.25 crashes per million VMT. The increase in crash rate after installation was 1.13 crashes per million VMT, or 36 percent. Specifically, the rate of increase for sideswipe crashes was 8 percent, and the rate of increase was 21 percent for rear-end crashes. 
Westbound Segment. The crash rate before installation was 2.91 crashes per million VMT, and 3.53 per million VMT after installation, an increase of 0.62 crashes per million VMT or 21 percent. The rate of increase was 35 percent for both sideswipe crashes and rear-end crashes.

The Wisconsin DOT concluded from its analysis that the variable message sign had an effect on traffic safety, notably an increase in the rate of sideswipe crashes. In addition, the report concluded that the greater increase in crashes for the eastbound segment was due to the orientation of the sign towards eastbound traffic. (This sign was removed 16 years after it had been installed, when the Milwaukee County Stadium was demolished. A similar sign was installed on the new stadium.)

\subsubsection{The Curriden Article}

A recent court case in Texas arose from a crash in an airport caused by a driver reading an electronic sign that listed departure and arrival times, and gate information. The driver stopped his vehicle to read information on the sign. A second vehicle swerved around the stopped vehicle and side swiped a vehicle in the adjacent lane, resulting in a three-vehicle crash. Two drivers were injured in the crash and sued the airline that owned the EBB. A jury found that the EBB was the indirect cause of a multiple vehicle crash at the airport and returned a negligence verdict against the airline. The airport subsequently removed the EBB. ${ }^{(5)}$

\subsection{Potential Safety Factors}

\subsubsection{Distraction}

The review of crashes presented previously suggests that EBBs may be associated with a higher crash rate under certain conditions. If this possibility is verified through further research, then it can be asked whether these crashes are a result of driver distraction in which the distracting stimulus is the EBB.

Distraction can be a framework in which to view EBBs and safety. The safety consequences of distraction from the driving task can be profound. Treat et al. ${ }^{(6)}$ found that driver inattention and improper lookout increase the likelihood of crash occurrence and are major factors underlying the causes of crashes. According to Wang, et al., ${ }^{(7)}$ an analysis conducted by the National Highway Traffic Safety Administration (NHTSA) of causal factors of crashes showed that distraction by sources external to the vehicle accounted for 3.2 percent of the crashes. The external sources included people, events, and non-specified objects. The NHTSA analysis did not identify the external objects, nor did it identify billboards as among the sources of distraction. However, the data suggest that, on occasion, external stimuli can be sufficiently distracting to drivers, causing or resulting in a crash.

Distracting Stimuli. One type of distracting stimulus is the unexpected event that results in an involuntary reaction. This type of stimulus is unanticipated and produces a surprise or orienting response - the person will redirect his or her attention to the new event to identify it and assess its significance. Such a stimulus may be an event that is not typical for that time or place, e.g., a flash of light, movement or sound.

A more subtle form of distracting stimulus can be one in which the stimulus has a less surprising quality, and thus presents more time for the driver to decide whether to attend to the stimulus and how much attention to direct to the stimulus. Dorneim ${ }^{(8)}$ documented that this has been has been 
a problem for pilots. In some situations, a pilot will occasionally attend more to a secondary task and neglect the primary task of flying the plane, sometimes resulting in a crash. Although the task of flying is obviously different from driving, there may be lessons to be learned for drivers. NASA is currently conducting research on ways to avoid this type of air crash. It may prove useful to check the progress of this research to see whether NASA research results have implications for driver distraction. Some of the research questions involve understanding how people know when to return their attention to a task, as well as identifying the limits of switching between tasks.

Measures of Distraction. For this project, driver distraction is characterized as deterioration in driving performance, the primary task, while attending to a second, non-driving task. The second task is subordinate to the driving task. An example of a non-driving task is operating an audiocassette system or using a cellular telephone. When the safe operation of the vehicle is degraded by the performance of the second task, the second task is defined as a "distractor."

Safe operation or control of the vehicle is recorded with measures of effectiveness (MOE) for driving. These measures include lateral deviation of the vehicle and maintenance of appropriate speed, as indicated by headway measures. Lack of control indicated by excessive lateral deviation or inappropriate speed could result from distraction, sleepiness, inability to see the road because of weather or lighting, poor perception of road geometry requirements, or other reasons. Since there are multiple factors that can contribute to lack of vehicle control, the design of a distraction study must take into account these other factors and ensure that they do not confound the design and allow misinterpretation of the data.

Lateral deviation can be measured by analysis of variability in steering wheel position, and/or varying distance of the vehicle from a lane marking on the road. When measuring lateral deviation, a certain amount of variability in deviation is expected. Greater-than-normal lateral variation may indicate a degree of lack of vehicle control. An example of lateral deviation occurs during the performance of a non-driving task such as the selection, orientation, and insertion of an audiocassette into the cassette player while performing the primary task of negotiating a curve. If the cassette operation is performed in the same manner and at the same rate as when the vehicle is motionless, there is a high likelihood of lateral deviation. This scenario of cassette operation would be an example of a distracting task.

Another measure of safe vehicle control is the maintenance of appropriate speed. One driving behavior that would lead to improper speed is the selection of a more or less constant speed (speed invariance) when nearby vehicles change speed. This could result in an unsafe headway condition. Lack of safe control due to improper speed selection could be due to reasons similar to those listed above for lateral deviation. Another behavior measured by speed is the slowing of a vehicle to view an item external to the vehicle. Braking for emergencies may also be considered for a measure of distraction.

\subsubsection{Conspicuity of Displays}

To what degree does an external, conspicuous stimulus unrelated to driving distract a driver from the driving task? This question is basic to the notion that a billboard may degrade driving performance by diverting attention away from the driving task. If a billboard degrades driving performance, it may be useful to identify the components of the billboard that can distract drivers. Some possible distracting components of a display are motion, complexity, and 
illumination. If such qualities are relevant to distraction, do they act alone or do they interact with each other? To the extent that these qualities are identifiable, it may be possible to understand their effect on distraction.

A brief review conducted by Hughes and Cole ${ }^{(9)}$ identified the physical properties of a conspicuous object. Important properties that contribute to conspicuity include object size, object contrast with its immediate background as well as the complexity of the background. An additional property is "the boldness of the graphics used to display a message."

According to Cole and Hughes, ${ }^{(10)}$ conspicuity consists of two types: attention conspicuity and search conspicuity. Attention conspicuity is the "...capacity of an object to attract attention, and...might be measured by the probability of the object being noticed when the observer has not had his or her attention directed to its likely occurrence." Search conspicuity is "... the property of an object that enables it to be quickly and reliably located by search." Cole and Hughes suggest that eye movement that is responding to a stimulus in the peripheral visual field can be used to infer attention conspicuity in the visual mode. Such movement may be a "quasireflex eye movement that is related to human defense reaction."(10)

Theeuwes ${ }^{(11)}$ challenged the view that conspicuous objects attract attention automatically. Instead, drivers will attend to the driving task and not a distractor. His past research showed that subjects ignored salient objects that were irrelevant to a search task. In a subsequent study, participants were instructed to locate a task-related stimulus (a blue sign) in a video taken from the driver's perspective. Distracting stimuli (e.g., a pedestrian in an orange jacket) were present in some experimental conditions, but not others. The results indicated that when the target stimulus, or blue sign, was in an expected location, the presence of the distractor had no impact. However, when the target was in an unexpected location, thus increasing the search time, the presence of the distractor increased the time required to locate the target above that due to expectation effects.

The visual environment affects the conspicuity of objects. Since drivers obtain travel related information by searching the visual environment for a target, such as a street sign, outdoor advertising can compete with targets of driving-related information. The concept of "visual noise" refers to non-target objects in an environment and can be used to determine a sign's conspicuity in a particular environment. Akagi et al. ${ }^{(12)}$ state that "Objects causing visual noise can be defined as objects that hinder drivers' field of view, such as billboards and buildings along roadsides." This study reported that increases in the visual noise (i.e., the number of signs in a roadway location) correlated with longer search time required for drivers to locate a target sign.

In a study performed by Hughes and Cole ${ }^{(9)}$ regarding the conspicuity of roadside objects, drivers reported "all the objects or things that attracted their attention" as they drove through 20 $\mathrm{km}$ of residential streets and arterial roads. Afterwards, they observed a film of the same route, taken from the driver viewpoint. Advertising displays accounted for 13.7 percent of reports in the driving study and 10.2 percent in the laboratory study. Driving related objects (road, traffic control devices (TCDs), vehicles, and people) accounted for 51.4 percent of reports in the driving task and 57.9 percent in the laboratory study. Other non-driving task elements included immediate and general roadway surroundings. Advertising elements were reported equally on arterial and shopping center routes, and more so than on residential streets. However, in 
residential streets, drivers directed more attention to non-driving related elements. This suggested a possible spare attention capacity.

A field study by Luoma ${ }^{(13)}$ analyzed driver eye fixations on roadside advertisements during a 50 $\mathrm{km}$ drive in Finland. Results indicated that accurate perception of advertisements was associated with longer fixation times $(2.3 \mathrm{sec})$ than the times for pedestrian markings and speed limit signs $(0.4 \mathrm{sec}$ to $0.5 \mathrm{sec})$. The author concluded, "...long fixation times indicate that the characteristics of roadside advertisements related to information ergonomics are poor.'(13) Information ergonomics is the practice of providing information in the most efficient way, such that viewers can access the information quickly and clearly.

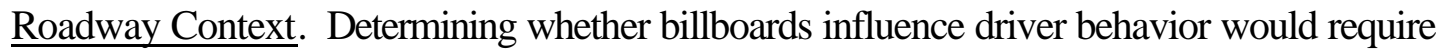
understanding the roadway context of a billboard. For example, roadway factors such as the angular distance of a billboard, billboard placement and volume characteristics of an intersection, may influence driver responsiveness to visual stimuli and the experience of workload. In this sense, information on the effect of the roadway context on driving performance should assist in defining appropriate billboard locations. Research on driver search behavior in high and low volume intersections by Rahimi, Briggs and Thorn ${ }^{(14)}$ in 1990, suggests that higher volumes of traffic affect driver eye and head movements. The research indicates that the greater visual complexity associated with the high volume intersection required drivers to search the environment more than in the low volume intersections. It can be conjectured that additional visual stimuli, such as billboards, may add additional demand to driver workload in high-volume intersections.

\subsubsection{Legibility}

One event that can be considered a distraction occurs when a driver passes a sign where the text has poor legibility. The weakness in legibility may be due to poor character font design, improper spacing of letters, or other factors. However, if the information is of sufficient interest, the driver may try to read all of the text anyway. Such a decision could take time away from the driving task thus increasing crash risk. If on the other hand, the sign had text that met legibility standards, less effort would be required to read the sign. Although this situation is a more subtle distraction than that due to perceived motion in a sign, it still could present potential for crash risk. Legibility information is available for CMSs. Although the CMS is restricted to providing roadway related information, its legibility requirements may be relevant to the design of the simpler EBB

Luminance and Luminous Contrast. Garvey and Mace ${ }^{(15)}$ examined CMSs to identify the features that contribute to their visibility. Both field and laboratory studies were employed following a review of the literature. Of particular interest in this report are the requirements for lighting, such as the luminance value and contrast ratio necessary for legible viewing. The study discussed requirements for displays such as LEDs, fiber optics, lamps, flip discs, and reflective discs. The authors provide guidelines that are aimed at improving the visibility of all CMSs, regardless of technology.

Minimum luminance values were recommended for CMS visibility. These values are based on the $85^{\text {th }}$ percentile driver accommodated at $198 \mathrm{~m}(650 \mathrm{ft})$. Age and position of the sun were two of the most significant factors when determining minimum luminance. Values are presented for drivers in two age ranges (16-40 and 65 or older). When the CMS is backlit (sun behind and 
above CMS) or under washout conditions (low sun shining directly on CMS), $1000 \mathrm{~cd} / \mathrm{m}^{2}$ is recommended for both age groups. This value accommodates less than 50 percent of older drivers at any luminance level with extreme sun angles. When the sun is directly behind the CMS, few if any people will be able to read the characters under any luminance level. When the sun is overhead the 65 years and over group still requires $1000 \mathrm{~cd} / \mathrm{m}^{2}$, but only $850 \mathrm{~cd} / \mathrm{m}^{2}$ are required for the younger group. During overcast or rain, $600 \mathrm{~cd} / \mathrm{m}^{2}$ is required for the older group and $350 \mathrm{~cd} / \mathrm{m}^{2}$ for the younger. For the nighttime condition, both groups require a luminance of $30 \mathrm{~cd} / \mathrm{m}^{2}$.

According to Garvey and Mace, ${ }^{(15)}$ there should be a minimum luminous contrast between the unlighted and lighted elements on a CMS; a maximum luminous contrast was not provided. Contrast orientation should always be positive, that is, the characters should be lighted against a dark or less luminous background. A negative contrast is likely to result in a 25 percent shorter legibility distance.

Contrast luminance for a CMS was determined with the formula:

$$
\frac{L_{t}-L_{b}}{L_{b}}
$$

where:

$$
\begin{aligned}
& L_{t}=\text { luminance of a character module with all of the elements "on" } \\
& L_{b}=\text { luminance of a character module with all of the elements "off." }
\end{aligned}
$$

The minimum acceptable contrast luminance is 5 , and the optimal contrast luminance varies from 5 to 50 .

A summary of existing literature on sign visibility performed by Kuhn, Garvey and Pietrucha, ${ }^{(16)}$ examined the two main research areas of sign detection; that is, sign conspicuity and sign legibility. The emphasis was on the more familiar and traditional sign rather than electronic signs. It is likely, however, that the design of an electronic sign would benefit from some of this information. A series of visibility guidelines for on-premise signs was presented. (An onpremise sign disseminates information that directly relates to the use of the property on which it is located.) Later research by $\mathrm{Kuhn}^{(17)}$ compared lighting methods (external illumination, internal illumination with opaque background, internal illumination with translucent background and neon) under day and night conditions to examine sign visibility features.

Claus and Claus ${ }^{(18)}$ addressed the issue of startling types of signs, such as those employing "flashing or animation to catch attention." These authors discuss different types of motion or movement. One of these is "...jumping arrows, or rapidly chasing or flashing lamp borders... (that) should perhaps be limited to midways and to rows of theater marquees." They did allow for other pictorial sequences that may be more acceptable as well as alternating displays such as the time and temperature display.

Alphanumeric Characters and Their Spacing. The design or selection of font type and the spacing between characters (letters), words and sentences are critical in achieving effective legibility of signs, especially when legibility is defined by the distance at which a sign can be read. Garvey \& Mace ${ }^{(15)}$ provided draft guidelines for the design of the elements and characters that compose a word and word groupings on a CMS, in which the character font is composed of 
light emitting elements. To achieve effective legibility, a number of features are considered. It is important to address each of the features, since they interact with each other. For example, to design an upper case character font, use a $5 \times 7$ matrix of light emitting elements. However, with a small matrix of this size, it is well to avoid thickening of a line in a character (e.g., as in an "I" or " $\mathrm{T}$ ") by adding another row or column of elements because the legibility distance is shortened by about 25 percent.

Font design for exterior signs should be simple without serifs. Additional information was provided on the height of the character, the proportion of the character or width-to-height ratio, and stroke width of the character. Further information was provided on the spacing between letters, between words and between lines of characters. Signs with light emitting elements have special characteristics. Light emitting elements provide high contrast between characters and background and thus provide superior performance over reflective signs at night. However, the light intensity requires careful adjustment. According to Garvey and Mace ${ }^{(15)}$ high contrast produced by lighted elements at night can "create halation or irradiation, blurring letters with wide stroke widths."

Message Length. A series of studies was performed by McNees and Messer ${ }^{(19)}$ to evaluate urban freeway guide signing. A study relevant to EBB issues examined the reading time required for guide signs. Study variables included "bits" (i.e., the amount of information on each panel) and number of sign panels. A typical sign panel contained an exit number, exit direction, cardinal direction, route number, and two destinations. It also included symbols such as a shield, and directional arrows. Examples of bits of information were: "I-395," "Washington, D.C." and "South." Each sign panel had, on average, six bits of information. The display time of the sign simulated the total time a driver would have available to read a guide sign in a typical freeway environment. The display times provided for reading the signs represented three traffic conditions: "extreme" (2.5 sec display time), "minimum" (4 sec display time), and "desirable" (6 sec display time). Median reading times for these conditions were: $1.7 \mathrm{sec}$ (extreme), $2.0 \mathrm{sec}$ (minimum), and $2.9 \mathrm{sec}$ (desirable). The results indicated that the time used to read the signs was dependent on quantity of information per sign as well as time available to perform the task. Based on these results, the authors concluded that the information content of a highway guide sign should not exceed six bits of information per panel.

\subsection{The Driver}

\subsubsection{Driver Age}

The analysis of distraction should consider the effect of driver age. If a significant portion of the driving population is more susceptible to distraction, then research on the relationship between distraction and safety should recognize this susceptibility. Such research could provide information about age-related differences regarding visual capability or reaction times that are relevant to driver reaction to EBBs. Both older drivers and young/inexperienced drivers are examined in this discussion.

The highway safety community recognizes that the probability of crash involvement varies with driver characteristics, most notably age. Highway data analysis demonstrates that the young driver and older driver populations have high crash involvement, and elevated injury and fatality rates. According to the Transportation Research Board's Special Report Number $229,{ }^{(20)}$ the high involvement rate of older drivers in crashes is second only to the rates of young drivers 
Experience and age may be important factors to consider in the evaluation of the effects EBBs have on safety. The research literature provides a firm foundation for stating that age and experience need to be considered. If EBBs are ultimately found to have a high degree of attention conspicuity - that they compel drivers to attend to them - then it is reasonable to expect that populations such as older or inexperienced drivers, who have less attention to spare, will be placed at greater risk by EBBs.

The Older Driver. According to Barr and Eberhard, ${ }^{(21)}$ the safety and mobility of older drivers, generally defined as 65 years of age and above, are highly relevant to transportation planning. Because of an increasingly aged population, the number and proportion of older drivers are rising. By 2020, Waller ${ }^{(22)}$ has estimated that 17 percent (50 million people) of the United States population will consist of people 65 years and older, compared to 12 percent in 1988. The proportion of older adults licensed to drive is increasing. For example, in 1980, 60 percent of older adults (at least age 65) were licensed drivers, compared to 70 percent in 1989 . These data point to the need to include older drivers in research programs on roadway safety, including the evaluation of EBBs and distraction.

Older drivers have a high crash risk per mile. ${ }^{(22)}$ They are involved in a disproportionate number of fatal crashes and multi-vehicle crashes where they were the responsible party, ${ }^{(23,24)}$ and are over-represented in crashes that involve turns, merges, and yielding the right of way. ${ }^{(25)}$

Recent studies performed by Ball and Owsley ${ }^{(26)}$ point to cognitive demands as influential factors in driving. Visual processing speed and the ability to handle selective and divided attention demands may have the greatest impact on crash rates. An increase in age did not directly contribute to crash involvement. However, an increase in age correlated with lower processing speed and decreased attention. The fact that attention and visual processing speed degrade with age may be symptomatic of the increasing inability of older drivers to encode and process all but the most important information in the driving environment.

The Younger Driver. The young driver (16 to 24 years old) is more likely to be involved in a crash than drivers of other ages, and a driver under 23 years of age is 2.5 times more likely to be killed in a crash than drivers 25 years and older, according to the NHTSA. ${ }^{(27)}$ Whereas the young driver crash risk on a per-mile driven basis is greater than the crash risk of other drivers, their risk decreases on the continuum from 16 to 24 years old, according to Lerner et al. ${ }^{(28)}$

Incidents involving younger drivers are attributed to age and experience-related factors. Widely recognized age-related factors reported by Decina et al. ${ }^{(29)}$ include risk-taking and alcohol consumption. Experience-related factors include the psychomotor, perceptual, and cognitive skills required for steering and maintaining speed, driving during high risk periods (such as at night), inefficient or inappropriate scanning behavior, poor hazard recognition, and poor driving judgment and decision-making.

The young driver demonstrates poorer coordination of separate driving tasks and tends to concentrate on one aspect of performance, such as maintaining lane position. ${ }^{(29)}$ According to Mournat et al., ${ }^{(30)}$ the visual scanning behavior of a young driver is less effective than that of mature drivers because the young driver tends to focus more closely in front of the vehicle. Furthermore, Miltenburg and Kuiken ${ }^{(31)}$ report that the inexperienced driver is likely to have attention drawn to irrelevant but "attention-getting" objects. The aforementioned research suggests that the young driver may be more vulnerable to distractions than the more mature 
driver. The data indicate that the young driver has weak situational awareness and relatively poor focus on the driving task itself. Thus, distracting stimuli, inside or external to the vehicle, may adversely affect the young driver.

\subsubsection{Driver Familiarity with Route}

Commuters and visitors require different information while traveling. The familiar driver requires more information on traffic conditions and incidents, whereas the visitor requires more navigational and guidance information. A field study of driver visual search and scan patterns performed by Mourant et al. ${ }^{(30)}$ showed that drivers' visual fixations on traffic, road and lane markers, and bridges and road signs decreased as the drivers became more familiar with the routes. One conclusion from these data is that drivers who are familiar with a roadway may be less likely to attend to familiar signs, including EBBs. Thus, differences between visitors and commuters in visual attention to commercial signs may be a relevant variable in assessment of distraction effects of EBBs since more eye-catching displays may be needed to attract the commuter.

\subsection{Measures of Effectiveness}

\subsubsection{Surrogates}

Commercial EBBs are designed to "catch the eye" of drivers. Their presence may distract drivers from concentrating on the driving task and the visual surrounds. Research in other areas share a concern about driver distraction and may be applicable to the question of EBBs and driving performance. Investigations of driver distraction and safety have notably focused on two cases: cellular telephone use while driving, and in-vehicle information displays. In each case, the application of a new technology raised concerns about driver distraction. The following sections highlight research in these areas.

Cellular Telephone Use in Vehicles. The number of cellular telephone users reported by Cain and Burris ${ }^{(32)}$ in 1998 was 63 million, and at a growth rate of 40 percent per year, the NHTSA ${ }^{(33)}$ estimates that the number of users will reach 80 million by 2000. The increase in the number of cellular telephone customers, in combination with high-profile crashes involving cellular telephone use, has raised public awareness of the safety aspects of in-vehicle telephone use and led to legislative initiatives aimed at restraining telephone use in vehicles.

Crash Risk Analyses. Redelmeier and Ticshirani ${ }^{(34)}$ performed an epidemiological study of crash risk associated with cellular telephone use linked customer telephone bills to crash records maintained at the New York Collision Reporting Center to identify telephone use at the time of a crash. The study concluded that cellular telephone use quadrupled the risk of a crash during the call. Another epidemiological study performed by Violanti ${ }^{(35)}$ found a 34 percent increase in risk of crash among vehicles with celluar telephones.

Application to EBBs. Using cellular telephones while driving imposes at least three tasks: first, manually manipulating the telephone, which could affect control of the vehicle; second, glancing at the telephone, which requires looking away from the roadway; and third, engaging in conversation, which may disrupt concentration. The relevance of information on cellular telephone use to EBBs lies in visual (glancing) and cognitive (mental engagement) behaviors. Viewing EBBs or using a telephone requires drivers to look away from the roadway for some 
period. Similarly, reading a sign could disrupt a driver's concentration, just as engaging in a telephone conversation might.

According to Cain and Burris, ${ }^{(32)}$ hands-free telephone use carries about the same risk observed in hand-held use, and a NHTSA report ${ }^{(33)}$ cites that a telephone conversation is a factor in crashes more frequently than dialing. Cain and Burris ${ }^{(33)}$ believe that the type of conversation is significant in determining crash risk, and McKnight and McKnight ${ }^{(36)}$ believe that complex and intense conversations the riskiest and simple conversation relatively risk-free. Thus, becoming mentally preoccupied can be as distracting to a driver as manually operating a telephone or glancing away from the roadway.

In-vehicle Information Systems. Advances in communications technology have enabled the development of electronic devices that display traveler-related information to drivers in transit. Such devices can potentially redirect (or distract) a driver's attention from the primary task of driving. An examination of in-vehicle distractions may contribute to an understanding for potential out-of-vehicle distractions such as EBBs.

The presence of in-vehicle devices that provide traveler-related information, such as turn-by-turn directions, has raised questions regarding the amount of time taken away from the driving task by the information display. One concern is that a driver will underestimate the amount of time required to use the device, take longer than expected, thus taking too much time away from the driving task. This is similar to the concern in which a driver spends too much time looking at a stimulus external to the vehicle.

In order to measure visual distraction associated with the use of in-vehicle devices, a methodological approach was developed based on eye glances. This method calculates the total number and average duration of eye glances required to operate specific in-vehicle devices. Data compiled from research in the late 1980's defined the average time for a single glance and the average number of total glances required to use a variety of devices. Devices were the speedometer, mirrors, standard radio, climate controls, smoking/lighting, fuel gage, heating/air conditioner, map, and others. For example, using the radio required $1.20 \mathrm{sec}$ of glance time and 3.5 total glances, and reading the map required $1.70 \mathrm{sec}$ of glance time, and 5.0 total glances. Wierwille and Tijerina ${ }^{(37)}$ performed one investigation into this issue that compared exposure levels for in-vehicle devices to number of crashes associated with the use of these devices. Exposure was the number of glances, multiplied by the time for a single glance, multiplied by the frequency of use. When the variety of in-vehicle devices was examined in light of both number of crashes and their exposure, a linear relationship resulted such that the greater the exposure, the greater the number of crashes. This study suggested that the "... .relative number of accidents is directly related to visual resource allocation for in-vehicle tasks." The data regarding amount of time used for in-vehicle devices reported in this study may be a useful starting point for estimating the maximum amount of time that a driver can attend to a distraction outside the vehicle.

\subsubsection{Current Measurement of Distraction}

It would be beneficial to measure the effect that EBBs have on driver distraction. Such measures for EBBs and other stimuli external to the vehicle have not yet been developed. However, there is one approach being developed for in-vehicle information systems that, with some refinement, may serve as a measure of EBB distraction. 
Olsson and Burns ${ }^{(38)}$ describe a peripheral detection task (PDT) that is designed to measure visual distraction and driver mental workload. This study included measures of reaction time and correct detection rate for drivers who were asked to report the presence of an LED dot shown briefly at slightly different locations on a windshield while: 1) driving on country roads and a motorway and 2) performing a secondary task while driving. The dots were projected 1123 degrees to the left of the straight-ahead view and 2-4 degrees above the horizon. This location approximates the visual angle that corresponds to a pedestrian or some roadside signs.

Statistically significant results indicated that a CD manipulation task and a backwards counting task required a longer performance time and resulted in fewer correct detections than the baseline driving task. Since these drivers missed more targets when performing a secondary task and because it took longer to report the targets that were spotted, the PDT may be useful in assessing the distractibility of in-vehicle systems. The authors briefly discuss the necessity of defining a criterion such as a percentage correct detection rate and/or reaction time that would define driver distraction.

If the PDT can be applied to in-vehicle systems, it may also be applicable to stimuli external to the vehicle such as EBB and tri-vision signs. It would be necessary to adapt the methodology from an in-vehicle task to a vehicle-external stimulus and to define a criterion for distraction. The PDT procedure might also be employed in addition to the driver performance measures described above, i.e., measures of lateral deviation and speed selection. 


\section{SYNTHESIS}

The objective of the literature review was to identify and summarize the potential safety effects of EBBs on driving behavior. The present discussion examines the results of that review.

One of the initial sections of the review sought research reports that directly approached the safety effects of EBBs on the driver by examining crash rates related to the EBB; unfortunately, this subject is not well documented. In most instances, researchers were not able to verify that an EBB was a major factor in causing a crash. Only one study since the 1980 review and one lawsuit were identified.

After presenting research that directly addressed the relationship of EBBs to crashes, the literature review examined research regarding distraction, conspicuity, and legibility. Studies were identified that verified that: an increase in distraction, a decrease in conspicuity, or a decrease in legibility may cause an increase in the crash rate. While all of the identified research was transportation related research, only the legibility research examined electronic signs (e.g., CMSs).

There is indication that individual differences in age and driving experience may be important considerations in driver distraction, and are relevant to understanding driver responses to the external environment. Furthermore, research regarding driver familiarity of their route demonstrated that visual fixations on roadway signs decreases as route familiarity increases. This research may show that there is a difference between commuter and visiting drivers.

While the surrogates that were identified in Section 2.6.1 are not related to EBBs, it is believed that the planning that is performed in these fields is useful to this review. Research concerning in-vehicle distractions caused by cellular telephones and navigation display was reviewed in an attempt to associate conditions in which driver distraction can be identified and to determine how a driver may react. Further review of these fields is warranted at a later date.

At this point, it appears that there is no effective technique or method appropriate for evaluating the safety effects of EBBs on driver attention or distraction. Crash studies can show that EBBs may increase the crash rate, but research regarding driver familiarity can argue that commuter drivers may not even look at an EBB. This example is nicely illustrated by the Milwaukee County Stadium's variable message advertising sign. A before and after crash analysis showed an increase in the crash rate after the installation of the sign, but not to the point to warrant its removal and the sign remained in-place for 16 years.

The literature review identified research that addressed particular characteristics of an EBB. For example, distraction, conspicuity and legibility research performed on CMSs is relevant to the contrast and luminance of an EBB. The following section of this document takes EBB research to the next level. It presents a research plan that will allow for a more complete understanding of the potential safety effects of EBBs on driver attention and distraction by pulling together the information that has been gathered from unrelated studies and recommend a research plan to help answer the knowledge gaps. 


\section{RESEARCH NEEDS}

The synthesis of the review indicated several areas in which more information would contribute to a better understanding of the safety implication of EBBs and tri-vision signs. These areas are expanded into research recommendations in this section. Each of these recommendations or research questions presented in this section reflect a concern for driving safety.

To obtain information regarding the influence of EBBs or tri-vision signs on driving performance, it is necessary to examine these displays in a variety of situations. For instance, it is possible that driving performance would be affected on curves but not on tangent road segments. The depiction of motion on a screen may be disruptive to driving whereas a static screen may not. The primary objective of the research to be proposed is to determine whether there are conditions under which EBB or tri-vision signs constitute a driving concern as indicated by crashes or other form of degraded driver performance. If such conditions are identified, then additional research may be required to gain a detailed understanding of the issue. These research goals will be identified as Research Questions.

Information that was available in an area that may support EBB safety was identified as Research Findings. This information primarily focuses on text issues, particularly with the legibility of letters and words; information regarding symbols or graphics was not identified. Since the identified research was not performed in an EBB context, it may be worthwhile to replicate selected research findings in conditions based on EBB requirements. Thus, some of the findings will be followed by research questions.

The issues described below have been researched to varying degrees. Some questions, such as the effect of a motion-based display on driving safety, have not been fully researched yet. Other issues, such as minimum exposure time for a display, have been addressed by states with little or no research basis. Questions on legibility have been addressed, but in a context for providing traffic information to drivers. The research questions fall into three general areas of highway safety: the roadway, EBBs and tri-vision signs, and the driver. The section on EBBs and trivision signs is presented in two parts: the first addresses relatively global aspects of the billboard such as motion phenomena and exposure time. The second part addresses the more detailed issues of individual letters and words.

\subsection{Roadway Characteristics}

Different roadway characteristics exert varying demands upon driver attention and skill. Particular roadway configurations and their characteristics may be more or less suitable for EBBs, and are important to consider when evaluating the safety effects of EBBs. The roadway characteristics listed below have special considerations relative to the issue of distraction and safety.

- Horizontal and Vertical Curves. Compared to tangents, curved roadway segments require more adept handling from drivers. Thus, any distraction presented by an EBB may be larger in conditions when the driver is experiencing greater demands.

Research Questions - Curves: Is driver performance affected adversely by the presence of EBB or tri-vision signs on vertical curves, horizontal curves or even at a tangent segment? What is the role of vehicle speed and posted speed in this question? What effect does the radius of the curve, or other features of the horizontal curve, have in this 
situation? Does vehicle speed change on a tangent segment in the presence of an EBB or tri-vision sign?

- Interchanges and Intersections. Demands made upon the driver increase at interchanges and intersections. For example, at highway interchanges, drivers execute multiple tasks, including controlling lateral position in their lane, maintaining appropriate headway and speed, and navigating through traffic as they merge or turn. At intersections, drivers are required to attend to multiple sources of potential conflicts, such as pedestrian crossings, changing traffic control devices, and turning maneuvers. Potentially distracting stimuli, including EBBs, may be particularly disruptive to drivers under the increased demands associated with interchanges and intersections. Current federal and state statutes prohibit the placement of roadside signs and displays near interchanges and intersections. EBBs offer a potential for driver distraction similar to or greater than conventional billboards, and should be considered to be subject to the same restrictions on placement near interchanges or intersections. Current state statues and regulations employ different values ranging from 152 to $305 \mathrm{~m}$ (500 to $1000 \mathrm{ft}$ ). The effects of EBBs and tri-vision signs on driver performance should be examined to determine if performance deficits are observed.

Research Questions - Intersections: Will an EBB or a tri-vision sign located near an intersection contribute to degraded driver performance? If driving performance is found to be degraded, then what should be the distance between this type of display and the intersection?

Research Questions - Interchanges: Will an EBB or a tri-vision sign located near an interchange contribute to degraded driver performance? If driving performance is found to be degraded, then what should be the distance between this type of display and the interchange?

- Work Zones. Drivers traveling in work zones need to be alert for changing traffic patterns, sudden stops, workers, pedestrians, and work equipment. Although drivers should reduce their speed in these zones, they often do not reduce speed sufficiently. This has resulted in special efforts by states to encourage safer driver behavior in such zones. Whatever the reason for current selection of improper speed in a work zone, it is possible that the presence of an EBB or tri-vision sign would aggravate the problem. Research about the effects of EBBs in work zones on safety should be performed, since the presence of additional visual distractions may elevate the risk of driver distraction and unsafe driving.

Research Questions - Work Zone: Will an EBB or a tri-vision sign that is located near a work zone promote unsafe driving? What constitutes close proximity to a work zone and how should the work zone dimensions be defined relative to the EBB?

- Distance between EBBs/Tri-vision Signs. Drivers may not direct sufficient attention to the driving task if EBB or tri- vision signs are too close to each other. Federal and state regulations address conventional billboards on this factor. Due to the greater conspicuity of EBBs relative to conventional billboards, it may be useful to reexamine the minimum distance between EBBs and tri-vision signs. 
Research Question - Distance Between EBB/Tri-vision Signs: Define an appropriate distance between EBBs and/or tri-vision signs that ensures driving safety.

\subsection{EBB and Tri-vision Sign Characteristics}

Research on EBBs should be directed toward the characteristics of EBBs, including placement, visual movement, and luminance. Research should include the characteristics of EBBs listed below.

- Message Content and Comprehensibility. If a driver attempts to read a display (either text or graphic) that is difficult to read due to factors such as excessive information, unfamiliar terms, and/or poor choice of word order, then the driver may not devote sufficient time to the driving task, thus raising a safety concern.

Research Finding-Amount of Information: An analysis of the amount of information on static guide signs recommended that a sign panel should present no more than six bits of information. Examples of a "bit" of information provided by McNess and Messer ${ }^{(19)}$ include "I-395, "Washington, D.C." and "South."

Research Question-Amount of Information: This finding should be replicated in an EBB and/or tri-vision sign context. The terms and symbols used in the context of a roadway environment may present somewhat different results due, perhaps, to familiarity of terms. Another feature that is different is the use of pixels on EBB displays versus the painted signs in the roadway study.

Research Questions - Quantity of Text: The Manual of Uniform Traffic Control Devices (MUTCD), ${ }^{(39)}$ Section 2E-21 (applicable to CMSs for use on freeway and expressway mainlines), states that a CMS should display no more than three lines of text. Further, there should be a maximum of 20 characters per line. An analysis of these numbers for the simpler EBB displays, in conjunction with analyses of exposure times, may be useful. The acceptable amount of information in the pictorial and/or dynamic display, both EBB and tri-vision sign, could be determined at the same time. In these situations, other display components such as graphics, motion and/or exposure time should be examined in conjunction with quantity of information.

- Exposure Times. The time intervals associated with the display of an image and the transition between images may be important to safe driving and effective driver understanding of the display. The design of an EBB or tri-vision sign message will be more effective when the time constraints for the driving task and the required time for effective message transmission are considered together. A related factor is the length of the transition interval between messages or images. Transition time can be important during the rotation of elements on a tri-vision sign due to the visual effects of the rotation. Transition in an EBB can be almost instantaneous. The minimum exposure time for a display and maximum time for display transition have been provided by some states.

Research Questions - Exposure Time: What factors determine the interval length for the safe display of a message? How can specific display times be determined? (For CMSs, the MUTCD 2000, ${ }^{(39)}$ Section 2E-21 states that "The entire message cycle should be readable at least twice by drivers traveling at the posted speed, the off-peak $85^{\text {th }}$ percentile speed, or the operating speed.") 
Research Questions - Transition Time: What is a safe transition time between messages? During the transition, should the display be completely dark? Should a transition interval between motion displays be a different time than a transition interval for static displays?

- Motion and Other Image Components. Some stimuli are particularly effective in attracting attention. It is not always clear which feature(s) of a complex stimulus is the most compelling. Motion is a highly likely candidate for an effective attention grabber. Motion can be provided in a billboard display in at least two ways. An EBB display provides motion when its lighted elements or pixels present an image in apparent movement across the display. An example is a high-resolution picture similar to a television image or video. Another example would be a text message sliding in from the side, top, or bottom. A tri-vision sign provides mechanical motion when its triangular elements rotate to present an alternate image. In this case, the motion is provided during a transition between displays. The motion component of an EBB or tri-vision sign may be more of a distraction than message content or pictorial arrangement. This possibility exists because a motion requires time and if a driver wants to see the entire movement for some inherent interest, then the driver will focus more on the motion display and less on the driving task. Note that the MUTCD 2000, ${ }^{(39)}$ Section 2E-21 states that, "Techniques of message display such as fading, exploding, dissolving, or moving messages shall not be used" for a CMS.

Research Questions - Motion Effects: To what extent will motion in an EBB or tri-vision sign contribute to degraded driver performance? What are the relevant dimensions of motion (e.g., presence vs. absence; low, medium or high speed; constant speed vs. variable speed; constant direction of moving item vs. change in direction)? How might motion interact with the content in a display to affect driver performance? Is the length of the interval during which motion occurs an important factor? Contexts to be considered for this research may include interchanges, intersections, curves, different vehicle speeds, and various TCDs including traffic signals.

Research Questions - Other Image Components: How should the components of the image, or their combination, (e.g., motion, color, message content, amount of information) be examined to determine which are most likely to be particularly distracting? Or is the distractibility of these components conditional to the specific situations?

- Maintenance. Poor maintenance of an EBB or tri-vision sign can affect driving safety. If the letters and words become difficult to perceive due to scratched protective covers or because elements are not functioning due to wear, drivers interested in the expected message may devote too much attention to interpreting the characters. One phenomena requiring maintenance that may be unique to programmed light emitting elements is the condition in which some of the lighted pixels in a display fail to illuminate, thereby removing part of the word. In the same display, other pixels that should be off are lighted instead. In some cases, the display presents a sort of abstract design that may be engaging for its own sake. Depending on the particular instance, the message becomes difficult if not impossible to read, thus lengthening the time that a driver attends to the display. 
Research Questions - Maintenance: Define the features of a sign that, if not maintained properly, contribute to driver safety issues. Develop criteria for achieving a minimal level of sign maintenance including a schedule and process for monitoring and repairing the sign.

\subsection{Research Findings in Legibility}

This section focuses on Research Findings that appear relevant to the use of text and graphical information on EBBs. These findings resulted from research on CMS displays that are used to transmit roadway information to drivers. The degree to which these findings are relevant may depend on the visual similarity between the EBB and the CMS. The CMS has a similar appearance to the simpler version of the EBB that was described in Section 2.1. Recall that the simpler version was characterized as employing a small character matrix for light emitted letters that are located on a dark background panel. It typically presents a limited number of words. The resemblance between CMS and EEB is likely to become less, however, with an opportunity for employing motion, a variety of colors, and higher resolution matrices. Such differences emphasize the need for research into EBB legibility. The present Research Findings are provided here as a starting point for that research.

Illegible letters, words and images promote longer reading times. This can result in a longer time for driver attention to be diverted away from the driving task. Because EBB letters are presented in a different medium than those in the more familiar road guide sign, they require special attention. The letters and numerals on a CMS or EBB are often formed from a group of lighted pixels or elements that are arranged in a rectangular matrix. The font or design of the letter is constrained by the number and arrangement of elements.

The resulting font is different than the familiar fonts seen on paper and painted surfaces in several respects. First, the latter family of fonts can take on a large variety of styles that take advantage of the flexibility of the brush or the dexterity of the type designer. Many of the simpler EBB displays, on the other hand, currently use a basic font matrix composed of few elements (e.g., 4x6, 5x7). This small number of elements severely limits the variety of font styles available and results in a relatively crude font style. Second, note that the discrete elements in the small matrix present a discontinuous letter "stroke" that is not present in the traditional medium, that is, the eye can perceive a separation between the light elements if the sign is not too distant. Third, the EBB matrix is represented by elements that emit light compared to the black print that is read under light. Fourth, the EBB matrix is viewed in both night and day conditions whereas the traditional printed page is viewed and read under only lighted conditions. Due to factors such as these, it is important to have research that directly addresses the legibility needs of the lighted pixel element display.

A recent summary of legibility data is available for CMSs on the roadway and was compiled by Garvey and Mace. ${ }^{(15)}$ This information was compiled from a field survey of in-use CMSs, laboratory experiments and static field studies, and a partially controlled dynamic field study. From these results, the authors developed recommendations for CMSs. Information selected from these recommendations is presented in this section as research findings that may be useful for EBB design. Note, however, that this information was developed for CMSs and may not be directly transferable to an EBB due to differences in how they are used. EBB signs may have different requirements than the CMS and this may lead to different findings when researched. 
Thus, information on CMS legibility should be considered only as approximate reference data for EBB design.

This section addresses only the legibility of letters and numerals that are composed of matrix elements for the simpler EBB. The legibility of pictures and other non-text graphics is not addressed. Legibility features that are addressed below include luminance, contrast, matrix size, letter size and proportion, and letter and letter group spacing.

- Luminance. In the determination of minimum luminance values for CMS signs, driver age and sun position relative to the CMS are important factors.

Research Finding - Minimum Luminance: Recommended minimum luminance values $\left(\mathrm{cd} / \mathrm{m}^{2}\right)$ for CMS visibility ${ }^{1}$ provided by Garvey and Mace ${ }^{(15)}$ are shown below:

Table 2. Recommended Minimum Luminance Values (cd/m2) for CMS Visibility.

\begin{tabular}{lccccc}
\hline & Sun Behind & Sun On Sign & Sun Overhead & Overcast/Rain & Nighttime \\
\hline $\begin{array}{l}\text { Young Driver } \\
(16-40)\end{array}$ & 1000 & 1000 & 850 & 350 & 30 \\
$\begin{array}{l}\text { Older Driver } \\
(65+)\end{array}$ & $1000^{2}$ & $1000^{2}$ & 1000 & 600 & 30 \\
\hline
\end{tabular}

Source: Garvey and Mace. ${ }^{(15)}$

${ }^{1} 85^{\text {th }}$ percentile driver accommodated at $198 \mathrm{~m}(650 \mathrm{ft})$.

${ }^{2}$ Will accommodate less than 50 percent of drivers at $198 \mathrm{~m}(650 \mathrm{ft})$ at any luminance level with extreme sun angles.

Luminance levels for night were recommended to be between 30 and $150 \mathrm{~cd} / \mathrm{m}^{2}$.

Research Question - Luminance In Inclement Weather: An important consideration for night viewing of an EBB is whether or not heavy moisture conditions such as fog, snow, or rain are present. These conditions may have a diffusing effect on luminance such that a sign with normal luminance may have altered contrast in fog conditions. It would be useful to define maximum luminance in fog conditions and various glare thresholds for young and older drivers.

- Contrast and Contrast Orientation. Clear discrimination of letters from their background is a basic requirement for seeing the letter and reading the text.

Research Finding - Contrast Luminance: A ratio of an effective range of contrast luminance for CMS letters against their background is between 5 and 50 (15). Five represents a relatively low contrast between letter and background. Fifty indicates a high contrast.

Research Finding - Contrast Orientation: Light text letters on a darker background are preferred. A black background or colored background is acceptable. ${ }^{(15)}$

- Matrix Size. The design of individual letters and numerals for the simpler EBB is based on a matrix of rows and columns in which each matrix element contains one "pixel." Each pixel can be selected to emit light or not emit light. The number of rows and 
columns in a matrix is established to support the design of a character (letter or numeral). The size (number of rows and columns) of the character matrix is often the same for the design of all letters in the alphabet unless a continuous line matrix or full matrix is available. A given letter or numeral is defined by which pixels in the matrix are illuminated. In the $5 \times 7$ font discussed by Garvey and Mace, ${ }^{(15)}$ an "I" is defined with 7 vertical pixels and an " $\mathrm{M}$ " is defined with a combination of 18 vertical and diagonal pixels. One issue for displays with larger pixels is to select a matrix with sufficient rows and columns to provide a legible character. If there are too few rows and/or columns, the design of the character font will result in a character that is difficult to recognize and read. If the size becomes overly large, space could be wasted for no noticeable increase in legibility. Maintenance may also increase due to an increasing number of lighted pixels.

Research Finding - Matrix Definition: A 5 x 7 matrix that used a single stroke font was found to be one of the most effective matrix sizes for characters used on a CMS. ${ }^{(15)}$ The researchers recommended against using a double stroke font. One example of a double stroke font is defined by using two columns of pixels to form a vertical element in a letter such as "F" or "H." The researchers report that double fonts yield legibility distances about 25 percent shorter than regular fonts.

Research Question - Matrix Definition: As indicated by the researchers, various legibility factors are difficult to examine apart from each other. While the single stroke 5 $\mathrm{x} 7$ matrix appears to be a generally robust minimum matrix size, it would be useful to replicate this finding for the simpler EBB context when analyzing other legibility factors.

- Letter Size and Proportion. The overall proportion of a letter and its components, as well as its height is an important determinant of the distance at which a letter can be recognized. The selection of these dimensions and proportions should consider a number of factors including posted speed and driver age.

Research Finding - Letter Height: Letter heights have been researched. For instance, a letter height of $457 \mathrm{~mm}$ (18 in) was recommended for a CMS on roadways with an 89$\mathrm{km} / \mathrm{h}(55-\mathrm{mi} / \mathrm{h})$ speed limit. This value is intended to accommodate drivers over 60 years of age. ${ }^{(15)}$

Research Finding - Letter Width-to-Height Ratio: Width-to-height ratio should be at least 0.7 for a CMS. Legibility distance increases as much as 10 to 15 percent as the width-to-height ratio is increased from 0.7 to 1.0 . Note, however, that this results in a corresponding increase in the width of a letter on the $\mathrm{CMS}^{(15)}$

Research Finding - Stroke-Width-to-Height Ratio: A stroke-width-to-height ratio of no more than 0.13 is recommended for the CMS letter. Factors that enter this ratio are driver age, time of day, luminous intensity of the pixel element and amount of moisture in the air. For example at night, halation or irradiation can occur with light emitting elements at night that results in blurring of elements and letters. The distance at which a letter is legible will decrease by as much as 10 percent as stroke width ratio approaches $0.2 .^{(15)}$

Research Question - Letter Height: The distance at which characters should be legible for roadway information functions may differ from the commercial requirements of the 
simpler EBB. The EBB requirements for letter height and proportion should be defined and examined with other relevant factors that determine letter height in an EBB context.

- Spacing Between Letters and Letter Groups. The degree of separation between letters influences their legibility. If they are too close, the letters appear to run together and require longer recognition time. This is particularly true at night for letters composed of light emitting elements. Because of the high contrast, luminous letters of the CMS tend to blur together more readily than the letters on standard signs. As a result, the separation between light emitted letters should be greater.

Research Finding - Inter-Letter Spacing: For CMS signs that do not allow proportional spacing between letters, research indicates an inter-letter spacing of one-half the letter height. ${ }^{(15)}$

Research Finding - Inter-Word Spacing: For CMS signs that have an inter-letter spacing of one-half the letter height or have proportional spacing, research indicates an inter-word spacing of the height of the letter. For inter-letter spacing 3/7 the letter height or less, inter-word spacing can be equal to $5 / 7$ the letter height. ${ }^{(15)}$

Research Finding - Inter-Line Spacing: An inter-line spacing of 70 percent of letter height is suggested for CMS signs with more than two lines of text. Twenty percent of letter height should be adequate for the separation between two lines of text. The 70 percent separation is important for providing legibility for the middle line when there are three lines of text. ${ }^{(15)}$

Research Question - Spacing: Commercial signs may employ different features than used in the research referred to in this section. For instance, if a higher resolution matrix were used to present a commercial logo symbol or lower case letters, then the requirement(s) for letter separation may change. Such features may benefit from further research.

\subsection{Driver Characteristics}

Research on distraction effects of EBBs should include the variables of driving skill and vulnerability to distraction. A primary driver characteristic that can be studied in this regard is driver age, especially since driver-related cognitive and physiological variables including reaction time, visual acuity, and attention-sharing capacity correlate with age. Using young and older drivers as a "design" driver may yield lower and/or upper limits of parameters in EBB and tri-vision sign variables. For example, since older drivers have greater sensitivity to glare than do younger drivers, including older drivers in research on sign glare is important when determining limits to sign luminance.

- Young Drivers. The literature review conducted in Task 2 showed that young drivers are slower to detect traffic hazards, especially if the hazard is distant or emerging, and that young driver "situation awareness" of the roadway is less integrated and less sensitive to context. Of particular importance to the present report are indications that young drivers may have difficulty handling distracting events that compete for attention, whether the source is in-vehicle or external to the vehicle.

Research Question - Young Drivers: Research should determine whether young drivers are more likely to demonstrate degraded driving performance in the presence of EBBs 
and tri-vision signs and if so, to what extent. This factor could be present in most, if not all, of the studies described above.

- Older Drivers. Cognitive and visual deficits increase the difficulty of the driving task for older individuals. For example, the speed of visual processing and the capacity to allocate attention in divided attention tasks decline with age. Yet, each of these attributes underlies driving performance. Research on the older driver should focus on their driving performance in comparison to other age groups when they are exposed to EBBs and trivision signs in roadway configurations of higher driving task difficulty.

Research Question - Older Drivers: Research should determine whether older drivers are more likely to demonstrate degraded driving performance in the presence of EBBs and tri-vision signs and if so, to what extent. This factor could be present in most, if not all, of the studies described above.

\subsection{Other Potential Driver Distractions}

In the literature review, research was presented on other types of stimuli that may distract a driver. These are the cellular telephone and the in-vehicle information display.

- Although research in cellular telephone and in-vehicle information displays does not currently appear to have direct application to EBBs or tri-vision signs, these analyses are ongoing and may still provide insights into the nature of driver distraction, the definition of distraction thresholds and approaches to minimizing distraction for safe driving.

Research Question - Monitoring of Other Driver Distraction Research: Continue to follow the results of research on driver distraction, particularly in the area of cellular telephones and in-vehicle information displays to determine what may be learned, either in general principles or specific information, that is applicable to addressing potential distractibility from EBBs and/or tri-vision signs. Will the peripheral distraction task be a useful tool in assessing the distractibility of stimuli external to the vehicle? What modifications need to be made to make it applicable for both research and perhaps, even, evaluation of proposed billboards?

\subsection{Future Research}

A wide range of research questions for EBB and tri-vision signs has been addressed above. The general approach to these issues has been to establish under which conditions, if any, EBBs and tri-vision signs are most likely to affect driving safety. The area for which the most potentially applicable research is currently available is legibility. Other areas such as length of exposure time have received attention through state regulation. Some research areas such as whether motion in a display has any potential safety effect on driving seem to have received practically no attention. Since there are several potential research areas, approaches to efficiency in the analyses are useful. When planning future research on EBB and tri-vision sign safety questions, criteria may be developed that prioritize the questions. Such criteria might include a determination of which questions are the most urgent, the availability of existing field data for analysis, and the possibility of performing laboratory research. A second approach examines the possibility of combining research questions in one study. Thus, after prioritization, it could be useful to determine which issues should be investigated independently versus in an integrated manner. 


\subsection{Research Methods}

This section briefly describes several research methods that may be applicable for the candidate research topics.

- Documentation Analysis. Two variations of this method are described. In the Before and After method, data (e.g., crashes) from a site without an EBB or tri-vision sign are compared to the data from the site after sign installation. If the latter number of crashes was substantially greater than the former, and there are no other significant changes to the site (i.e., change in volume, average speed, new construction, etc.) during the comparison times, then one can argue that the sign was associated with increased crashes. A variation of this approach compares the site of interest to a control site during the same period. This method compares data from an EBB or tri-vision sign site to data at a comparable, control site without a sign.

- Field Study. Field studies normally have observers collect data on driver and vehicle behavior at the site(s) instead of performing an analysis of documentation. If there were a substantial difference in quantity of behaviors, there would again be reason to argue that the EBB was associated with changed driver behavior. When this type of study is compared to the study of documentation, this study usually has more controlled conditions of observation as well as the advantage of examining more behaviors (e.g., swerving, braking) than just crashes. The analysis of documentation, however, is more likely to provide a greater number of crashes since the data collection period is likely to be longer.

- Test Track. Another method shares some of the advantages of a field as well as a laboratory study. A simulation of infrastructure elements such as pavement and signs is avoided. The dynamics of the vehicle is not a problem. In addition experimenter can control instructions to the driver, provide signs and objects of any design, repeat trials, and control presentation of stimuli. The use of a test vehicle in this situation could avoid crashes with other cars while allowing observation and documentation of lane keeping, speed, and other behaviors.

- Simulation. A laboratory study allows the researcher to examine specific conditions by simulating scenarios with a combination of hardware and software. The fidelity of the simulation can vary depending on the kind of research question being asked. The fidelity will also depend on the type of apparatus available to study the research question. Lane deviation, change in speed, and crashes can be measured in the laboratory. An advantage of the laboratory is the capability to provide a realistic context for the study that does not expose the participant to actual danger. 


\section{ANNOTATED BIBLIOGRAPHY}

The following annotated bibliography summarizes three research papers on the possible distraction effects of systems that are located inside the vehicle. The references cited and summarized herein represent a sample of the extensive research literature on possible driver distraction from in-vehicle systems. This section briefly describes several studies that were evaluated in the present research effort, but were not included in the literature review itself.

1. Gellatly, A.W., and Kleiss, J.A. (2000). "Visual Attention Demand Evaluation of Conventional and Multifunction In-vehicle Information Systems." In: Proceedings of the IEA 2000/HFES 2000 Congress. Joint International Ergonomics Association $14^{\text {th }}$ Triennial Congress and Human Factors and Ergonomics Society $44^{\text {th }}$ Annual Meeting July 29, 2000-August 4, 2000.

This paper presents the results of a study of driver responses to executing conventional in-vehicle tasks and to operating a novel re-configurable, multifunction information system inside the vehicle. Six older and six younger drivers operated an instrumented test vehicle along a two-lane divided highway. Visual scanning behavior and driving task performance were measured while the research participants executed conventional tasks (e.g., climate control, audio control, and cellular telephone use) and advanced /future tasks (e.g., e-mail, navigation, audio, voice and video communications). The results showed that drivers completed all the tasks by means of a series of 1-1.5 sec glances to the in-vehicle display/control systems. Mean glance frequency increased linearly with mean task completion time, but mean glance duration remained constant over the range of mean task times observed. Mean task completion times were about twice as long for the re-configurable, multifunction information system as for the conventional in-vehicle devices. Certain driving task variables were correlated with mean task completion time. Both speed variability and lane variability (peak lateral acceleration) increased linearly as a function of mean task completion time. Although variability within the driving lane increased with task time, lane departure did not. Thus the research participants tended to stay in the lane, but exhibited more aggressive lateral position adjustments as the in-vehicle tasks became more complex and took longer. Overall, the data revealed a decrement in driving performance as the in-vehicle tasks took more time to complete. Therefore one design goal for any in-vehicle display/control device should be to minimize overall task completion time.

2. $\quad$ Rockwell, T.H. (1988). "Spare Visual Capacity in Driving - Revisited." In: A.G. Gale, M.H. Freeman, C.M. Hasleman, P Smith and S.P. Taylor (Eds.), Vision in Vehicles II. North Holland: Elsevier Science Publishers.

This paper summarizes a series of studies on in-vehicle visual sampling. The data were collected from 106 research participants in over 200 highway trips ranging in duration from 45 minutes to 1 hour. The studies measured off-road glances made by the drivers while completing a variety of in-vehicle tasks. Over 6,000 off-road glances were recorded. The in-vehicle tasks consisted of checking the speedometer, adjusting all three mirrors (left, right and rear-view), adjusting the stereo system (volume and tuning controls) and using a touch-screen CRT display. While the mean number of glances varied considerably from 1 glance to 40 glances, depending on the task, the average glance durations were extremely consistent, ranging from 1.27 to $1.42 \mathrm{sec}$ for stereos and mirrors. Older drivers tended to require 20 percent more glances to execute a given command than younger drivers. Traffic density and highway geometrics had a substantial effect on average glance duration. While driving in dense traffic at high speeds on curves with short 
headway distances, participants exhibited average glance durations that were 20 percent shorter for both stereo and mirror tasks. Thus glance durations are affected more by the requirements of the driving task than by the requirements of the in-vehicle task. As concerns the design of invehicle display/control devices, good design will be reflected more by a smaller number of glances than by shorter glances at the device.

3. Wierwille, W.G. (1993). "Visual and Manual Demands of In-car Controls and Displays." In: Smith and Solame (Eds.), Automotive Ergonomics. New York: Taylor and Francis.

This chapter synthesizes a series of different studies by different researchers on the visual demands of in-vehicle tasks. Five types of tasks are defined, ranging from almost automatic manual only tasks, such as setting the directional signal lever, to complex visual-manual tasks, such as interacting with a navigational map display. A time-sharing model was developed to describe how drivers gather in-vehicle information. The model results in a driving strategy where short glances are made away from the driving task until the necessary in-vehicle information has been gathered. These in-vehicle glances tend to be between 1.0 and $1.6 \mathrm{sec}$. After each glance, the driver returns to the visual driving task. Compensatory visual sampling strategies have been demonstrated in studies where an apparatus periodically blocked the driver's forward view of the road for brief periods. In addition, forward view of the road increases with increasing traffic, a more difficult roadway or strong crosswinds. As concerns the older driving population, for a given in-vehicle task, single glance times and the number of glances into the vehicle both increase with age. The transition time between the forward view and the in-vehicle view also increases with age. Several remedies are suggested to minimize the visual load of invehicle tasks. These include the use of heads-up displays, virtual image displays and displays located near the top of the vehicle instrument panel. Other remedies include the use of auditory displays and training on improved visual sampling techniques. Designers of in-vehicle displays and controls are urged to minimize the demands of in-vehicle tasks. Some suggestions include avoiding clutter and improving labels and legends. Two areas are identified where future research is needed: 1) expansion and refinement of models of in-vehicle task performance and 2) better guidelines for in-vehicle task communications. 
APPENDIX A: EXAMPLES OF ELECTRONIC BILLBOARDS

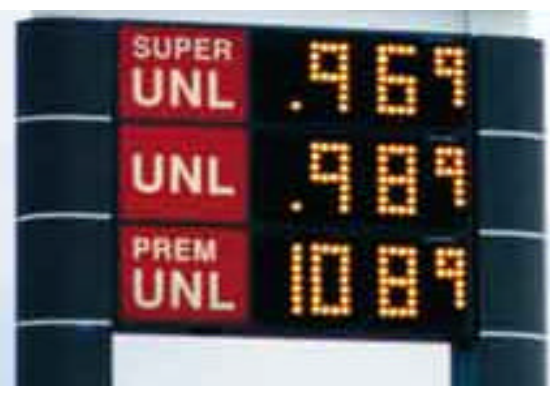

Incandescent Light Sign

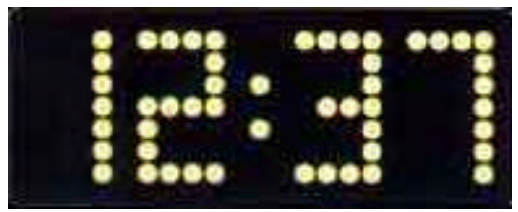

Incandescent Light Sign

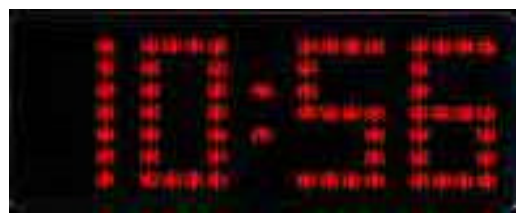

LED Sign 

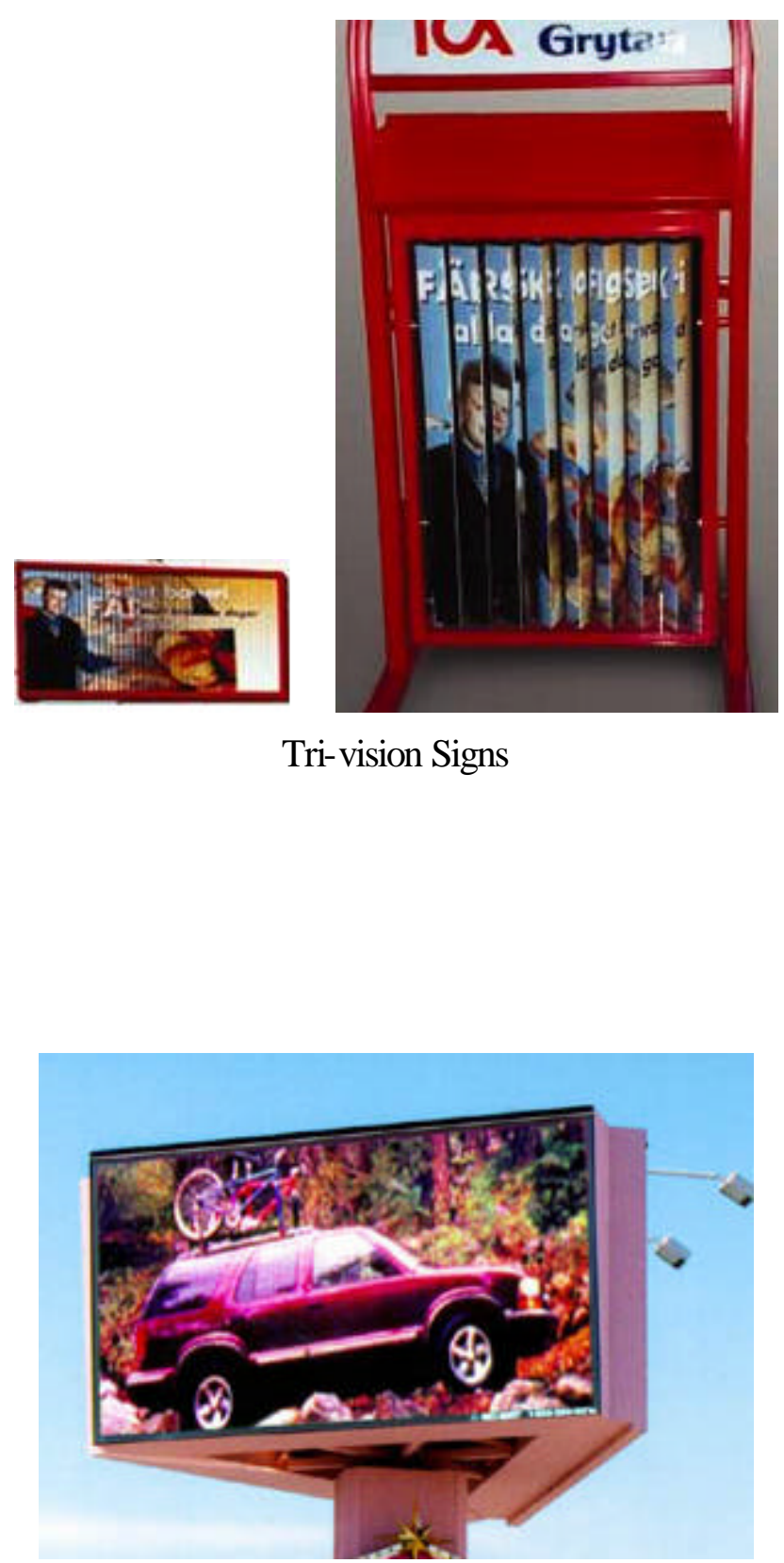

Video Color LED 


\section{APPENDIX B: OUTDOOR ADVERTISING: STANDARD DEFINITION}

Most states define the term "sign" using the following standard definition. States will vary specific wording, but this definition reflects the concept most states use.

"Sign" means any outdoor advertising sign, display, device, notice, figure, painting, drawing, message, placard, poster, billboard or other thing which is designed, intended or used to advertise or inform any part of the advertising or informative contents of which is visible from any place on the main-traveled way or any portion of an interstate highway or primary highway."

\section{Definition exceptions:}

Some states use the term "outdoor advertising device."

California adds "light or other thing."

Colorado adds "or other contrivance."

Florida - sign includes "any combination of structure and message."

Idaho adds "light device."

Massachusetts adds "whether fixed or movable."

As was noted in the literature review, few states define the term "electronic billboard." However, the definition above, with the catchall phrase "or other thing" appears broad enough to include electronic billboards in the standard definition of the term "sign."

\section{Statutory Prohibitions:}

The following list summarizes the statutory prohibitions identified during the review of state statutes and regulations. These prohibitions appear to apply to the standard "sign" as defined above, and are not directly targeted towards electronic billboards.

- Moving Parts/Animation: Eleven states prohibit moving or animated parts in signs, unless the signs are a public service announcement. A few states make an exception for movement related to the changing of a sign.

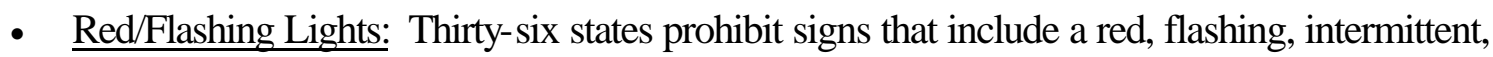
or moving light, unless it is a public service display.

- Glare: Thirty-six states prohibit signs that are not sufficiently shielded to prevent beams or rays of light from causing a glare or vision impairment that affects driver vision.

- Interfering with Traffic Control Devices: Fifteen states include language prohibiting the placement of signs that obscure or interfere with TCDs. Twenty-nine states include language that prohibits signs that are illuminated in such a way as to obscure or interfere with TCDs.

- $\quad$ Timing Limit: Twelve states include some type of timing limit for the viewing of signs. Of these, only eight apply to EBBs or other types of signs with changing messages.

- $\quad$ Sign spacing: Twenty-nine states include spacing requirements for location of signs on interstate or primary highway systems. Twenty-one include similar limits on sign spacing along other state highways. Twenty-two include limits on the spacing of directional signs along interstate or primary highway systems. 
- Language Usage: A number of states prohibit the use of wording that implies a traffic control or highway emergency (for example, use of the word "Stop"). Several states also prohibit the use of TCD signs or symbols (such as the eight-sided stop sign) in signs.

\section{Potential Issues:}

Based on this review of state statutes, the following are issues that embody the statutory and regulatory prohibitions adopted by states for conventional signs, and that may pertain to EBBs:

- Red, flashing, intermittent or moving lights,

- Glare,

- Use of TCD symbols and words,

- Illuminated or placement interfering with a TCD,

- Spacing, and

- Timing Limits.

Of the potential issues, timing limits may be the one issue where additional or expanded research would have the most significant benefit. The results of the state statutory review are shown in Appendix C. 


\section{APPENDIX C：RESULTS OF STATE STATUTORY REVIEW}

\begin{tabular}{|c|c|c|c|c|c|c|c|c|}
\hline & \multicolumn{8}{|c|}{ State Statutory References to Possible "Guidelines" } \\
\hline $\begin{array}{l}\text { Prohibitions on } \\
\text { Signs... }\end{array}$ & $\begin{array}{l}\text {...with red, } \\
\text { flashing, } \\
\text { intermittent, or } \\
\text { moving lights, } \\
\text { unless it is a } \\
\text { public service } \\
\text { display }\end{array}$ & $\begin{array}{l}\text {...that are not } \\
\text { sufficiently } \\
\text { shielded to } \\
\text { prevent beams or } \\
\text { rays of light from } \\
\text { causing a glare } \\
\text { or vision } \\
\text { impairment that } \\
\text { affects driver } \\
\text { vision }\end{array}$ & $\begin{array}{l}\text {...that are } \\
\text { placed so as } \\
\text { to obscure or } \\
\text { interfere with } \\
\text { traffic } \\
\text { control } \\
\text { devices }\end{array}$ & $\begin{array}{l}\text {...that are so } \\
\text { illuminated as to } \\
\text { obscure or } \\
\text { interfere with } \\
\text { traffic control } \\
\text { devices }\end{array}$ & $\begin{array}{l}\text {...located on interstate } \\
\text { or primary highway } \\
\text { outside of zoning } \\
\text { authority of } \\
\text { incorporated cities } \\
\text { within } 500 \mathrm{ft} \text { of an } \\
\text { interchange or } \\
\text { intersection at grade } \\
\text { or safety roadside rest } \\
\text { area }\end{array}$ & $\begin{array}{l}\text {...other state } \\
\text { highway says - } \\
\text { 300 ft limit }\end{array}$ & $\begin{array}{l}\text {...directional signs } \\
\text { may not be located } \\
\text { within } 200 \text { ft of an } \\
\text { interstate, or } \\
\text { intersection at grade } \\
\text { along the interstate } \\
\text { system or oth er } \\
\text { freeway, or within } \\
2000 \text { ft of a rest or } \\
\text { scenic area or } \\
\text { parkland }\end{array}$ & ...timing limit \\
\hline Alabama & Yes & Yes & Yes & Yes & Yes & & Yes & \\
\hline Alaska & & & & & & & & \\
\hline Arizona & Yes & Yes & & Yes & & & Yes & \\
\hline Arkansas & Yes & Yes & & Yes & Yes & & Yes & \\
\hline California & Yes & Yes & & Yes & Yes & Yes & Yes & $\begin{array}{l}4 \text { sec-message } \\
\text { display, } 1 \text { sec- } \\
\text { message change }\end{array}$ \\
\hline $\begin{array}{l}\text { Colorado } \\
\text { NOTE: prohibits } \\
\text { signs which have a } \\
\text { moveable advertising } \\
\text { face permitting any } \\
\text { change in sign } \\
\text { content or message }\end{array}$ & Yes & Yes & Yes & Yes & Yes & Yes & Yes & \\
\hline Delaware & Yes & Yes & & Yes & Yes & Yes & Yes & \\
\hline Florida & Yes & & & Yes & $\begin{array}{l}1500 \mathrm{ft} \text { on interstate } \\
1000 \mathrm{ft} \text { on federal aid } \\
\text { primary highway }\end{array}$ & & & \\
\hline $\begin{array}{l}\text { Georgia } \\
\text { NOTE: Prohibits } \\
\text { signs with moving or } \\
\text { animated parts unless } \\
\text { certain conditions are } \\
\text { met }\end{array}$ & Yes & Yes & & Yes & Yes & Yes & Yes & $\begin{array}{l}\text { Conditions: Message } \\
\text { fixed for at least } 10 \\
\text { sec, message } \\
\text { changed in } 3 \mathrm{sec} \text { or } \\
\text { less, } 5,000 \mathrm{ft} \text { spacing, } \\
\text { default freezing sign } \\
\text { if malfunction occurs }\end{array}$ \\
\hline
\end{tabular}




\begin{tabular}{|c|c|c|c|c|c|c|c|c|}
\hline \multicolumn{9}{|l|}{ Hawaii } \\
\hline $\begin{array}{l}\text { Idaho } \\
\text { NOTE: adds in blue } \\
\text { lights }\end{array}$ & Yes & Yes & & Yes & $\begin{array}{l}\text { Yes between displays } \\
\text { on interstate or primary } \\
\text { highway or } \\
\text { public/scenic areas } \\
1000 \mathrm{ft} \text { from an } \\
\text { interchange or rest area }\end{array}$ & & Yes & $\begin{array}{l}\text { Exposure time is } \\
\text { long enough at } \\
\text { maximum speed } \\
\text { limit for sign } \\
\text { message to be } \\
\text { readable and } \\
\text { comprehensible }\end{array}$ \\
\hline Illinois & Yes & Yes & Yes & Yes & Yes & & Yes & \\
\hline $\begin{array}{l}\text { Iowa } \\
\text { NOTE: Prohibits } \\
\text { animated or moving } \\
\text { parts in a sign }\end{array}$ & Yes & Yes & & Yes & Yes & Yes & & $\begin{array}{l}\text { Tri-vision signs }-4 \\
\text { sec minimum } \\
\text { display, two sec for } \\
\text { transition }\end{array}$ \\
\hline $\begin{array}{l}\text { Indiana } \\
\text { NOTE: Prohibits } \\
\text { animated or moving } \\
\text { parts }\end{array}$ & Yes & Yes & & Yes & Yes & Yes & Yes & \\
\hline Kansas & Yes & Yes & Yes & Yes & & & Yes & \\
\hline $\begin{array}{l}\text { Kentucky } \\
\text { Prohibits animation } \\
\text { and movement } \\
\text { except for movement } \\
\text { on and off of the sign }\end{array}$ & Yes & Yes & Yes & Yes & & Yes & & $\begin{array}{l}\text { Total message } \\
\text { displayed within } 10 \\
\text { sec, with each } \\
\text { segment having a } \\
\text { display time of } 2 \mathrm{sec} \\
\text { including change } \\
\text { time }\end{array}$ \\
\hline $\begin{array}{l}\text { Louisiana } \\
\text { NOTE: Statute } \\
\text { obtained does not } \\
\text { have information on } \\
\text { restrictions }\end{array}$ & & & & & & & & $\begin{array}{l}\text { Signs must be readily } \\
\text { viewed for a time of } \\
5 \mathrm{sec} \text { from the } \\
\text { roadway at posted } \\
\text { speed limit }\end{array}$ \\
\hline \multicolumn{9}{|l|}{ Maine } \\
\hline Michigan & Yes & Yes & & Yes & Yes & Yes & Yes & \\
\hline $\begin{array}{l}\text { Massachusetts } \\
\text { NOTE: Prohibitions } \\
\text { appear to be adopted } \\
\text { by reference } \\
\text { incorporating federal } \\
\text { regulations }\end{array}$ & & & & & & & & $\begin{array}{l}\text { Not more than } 3 \\
\text { rotating or alternate } \\
\text { messages may be } \\
\text { displayed on a sign }\end{array}$ \\
\hline
\end{tabular}




\begin{tabular}{|c|c|c|c|c|c|c|c|c|}
\hline Minnesota & Yes & Yes & & Yes & Yes & & & \\
\hline Mississippi & Yes & Yes & Yes & Yes & Yes & Yes350 ft & & \\
\hline Missouri & Yes & Yes & Yes & Yes & Yes & Yes & & \\
\hline Montana & Yes & Yes & & Yes & & & Yes & \\
\hline \multicolumn{9}{|c|}{$\begin{array}{l}\text { New Hampshire } \\
\text { NOTE: Statute has } \\
\text { no language on any } \\
\text { prohibitions or } \\
\text { restrictions. }\end{array}$} \\
\hline Nebraska & Yes & Yes & Yes & & & & & \\
\hline Nevada & Yes & Yes & & Yes & Yes & Yes & & $\begin{array}{l}\text { Minimum display } \\
\text { time of } 6 \mathrm{sec} \text {, } \\
\text { maximum change } \\
\text { interval of } 3 \mathrm{sec}\end{array}$ \\
\hline $\begin{array}{l}\text { New Mexico } \\
\text { NOTE: Prohibits } \\
\text { animation or movin } \\
\text { parts }\end{array}$ & Yes & Yes & Yes & Yes & Yes & & Yes & \\
\hline $\begin{array}{l}\text { New Jersey } \\
\text { NOTE: Prohibits } \\
\text { animation and } \\
\text { moving parts }\end{array}$ & Yes & Yes & Yes & Yes & Yes & & Yes & $\begin{array}{l}\text { Minimum message } \\
\text { time, } 4 \mathrm{sec} \\
\text { Maximum change } \\
\text { time, } 2 \mathrm{sec}\end{array}$ \\
\hline $\begin{array}{l}\text { New York } \\
\text { NOTE: }\end{array}$ & Yes & Yes & Yes & Yes & Yes & Yes & & \\
\hline $\begin{array}{l}\text { Prohibits animatio } \\
\text { or moving parts } \\
\text { except for public } \\
\text { service } \\
\text { announcement. }\end{array}$ & & & & & & & & \\
\hline North Carolina & Yes & Yes & & Yes & Yes & Yes & & \\
\hline
\end{tabular}




\begin{tabular}{|c|c|c|c|c|c|c|c|c|}
\hline North Dakota & Yes & Yes & & & Yes & Yes & Yes & \\
\hline $\begin{array}{l}\text { Ohio } \\
\text { NOTE: } \\
\text { No statutory } \\
\text { information obtained }\end{array}$ & & & & & & & & \\
\hline Oklahoma & Yes & Yes & & Yes & & & & \\
\hline Oregon & Yes & Yes & Yes & & & & Yes & \\
\hline Pennsylvania & Yes & Yes & & Yes & Yes & Yes & Yes & \\
\hline $\begin{array}{l}\text { Rhode Island } \\
\text { Note: Prohibits } \\
\text { animation and } \\
\text { moving parts }\end{array}$ & & Yes & Yes & & Yes, $750 \mathrm{ft}$ & Yes $250 \mathrm{ft}$ & & \\
\hline South Carolina & Yes & Yes & & & Yes & Yes & Yes & $\begin{array}{l}\text { Viewing time } 5 \mathrm{sec} \\
\text { from roadside when } \\
\text { traveling at speed } \\
\text { limit }\end{array}$ \\
\hline Tennessee & Yes & Yes & & Yes & Yes $1000 \mathrm{ft}$ & Yes $500 \mathrm{ft}$ & Yes & \\
\hline $\begin{array}{l}\text { Texas } \\
\text { NOTE: No statutory } \\
\text { literature included in } \\
\text { file }\end{array}$ & & & & & & & & \\
\hline Vermont & & & & & & & & \\
\hline Virginia & Yes & Yes & & Yes & Yes & & Yes & \\
\hline $\begin{array}{l}\text { Washington } \\
\text { NOTE: } \\
\text { Prohibits moving } \\
\text { parts and animation }\end{array}$ & Yes & Yes & Yes & & & & & $\begin{array}{l}\text { If sign change } \\
\text { exceed } 4 \text { sec, turn } \\
\text { sign off during } \\
\text { change }\end{array}$ \\
\hline Washington, DC & & & & & & & & \\
\hline West Virginia & Yes & Yes & & & Yes & Yes & & $\begin{array}{l}\text { Change time of } 5 \mathrm{sec} \\
\text { max without written } \\
\text { approval }\end{array}$ \\
\hline Wisconsin & Yes & Yes & & Yes & Yes & Yes & & \\
\hline Wyoming & Yes & Yes & Yes & & Yes & Yes & Yes & \\
\hline Total of 42 states & 36 & 36 & 15 & 29 & 28 & 21 & 22 & \\
\hline
\end{tabular}

NOTE: Ten (10) states prohibit animation or moving parts except on public service announcements. 


\section{REFERENCES}

1. Craford, M, Holonyak, N., and Kish, F., Jr. (2001). "In Pursuit of the Ultimate Lamp." Scientific American, 284, pp. 62-67.

2. Arkansas Highway Department (1967). Regulations for Control of Outdoor Advertising Policy. Little Rock, Arkansas Highway Department.

3. Wachtel, J. and Netherton, R. (1980). Safety and Environmental Design Considerations in the Use of Commercial Electronic Variable-Message Signage. Report No. FHWA-RD-80051. Washington, D.C: Federal Highway Administration.

4. Wisconsin Department of Transportation (1994). Milwaukee County Stadium Variable Message Sign Study. Wisconsin, USA: Internal Report, Wisconsin Department of Transportation.

5. Curriden, M. (2000). "Juries That Take Action Beyond the Law Have Deep Roots." The Dallas Morning News. Obtained from the World Wide Web: http://www.dallasnews.com/juries/101414_jurytwo_25buss.html

6. Treat, J.R., Tumbas, N.S., McDonald, S.T., Shinar, D., Hume, R.D., Mayer, R.E., Stanisfer, R.L., and Castellan, N.J. (1979). Tri-Level Study of the Causes of Traffic Accidents. Washington, DC: National Highway Traffic Safety Administration.

7. Wang, J., Knipling, R. and Goodman, M. (2000). "The Role of Driver Inattention in Crashes: New Statistics from the 1995 Crashworthiness Data System." Obtained from the August 2000 Driver Distraction Internet Forum sponsored by the National Highway Traffic Safety Administration on the World Wide Web.

8. Dornheim, M.A. (2000). "Crew Distractions Emerge as New Safety Focus." Aviation Week and Space Technology, 153(3), pp. 58-60.

9. Hughes, P.K. and Cole, B.L. (1986). "What Attracts Attention When Driving?" Ergonomics, 29(3), pp. 377-391.

10. Cole, G.L. and Hughes, P.K. (1984). "A Field Trial of Attention and Search Conspicuity." Human Factors, 26(3), pp. 299-313.

11. Theeuwes, J. (1996). "Visual Search at Intersections: An Eye-Movement Analysis." In: A.G. Gale, I. Brown, C. Haslegrave, and S. Taylor (Eds.), Vision in Vehicles: VI. New York: North Holland Press, Elsevier Science Publishers.

12. Akagi, Y., Seo, T, and Motoda, Y. (1996). "Influence of Visual Environments on Visibility of Traffic Signs." Transportation Research Record, No. 1553, pp 52-58. Washington, DC: National Academy Press.

13. Luoma, J. (1988). "Drivers' Eye Fixations and Perceptions.” In: A.G. Gale, M. H. Freeman, C.M. Hasleman, P. Smith, and S.P.Taylor, (Eds

14. Rahimi, M., Briggs, R. and Thorn, D. (1990). “A Field Evaluation of Driver Eye and Head Movement Strategies toward Environmental Targets and Distractors." Applied Ergonomics, 21(4), pp. 267-274.

15. Garvey, P.M. and Mace, D.J. (1996). Changeable Message Sign Visibility. Report No. FHWA-RD-94-077. Washington, D.C: Federal Highway Administration. 
16. Kuhn, B.T, Garvey, P. and Pietrucha, K.M. (1997). "Model Guidelines for Visibility of OnPremise Advertisement Signs." Transportation Research Record, No. 1605, Washington, D.C.: National Academy Press.

17. Kuhn, B.T. (1999). "The Impact of Illumination on Typical On-Premise Sign Visibility.” ITE Journal, 4, p. 64.

18. Claus, R.J., and Claus, K.E. (1971). Visual Environment: Sight, Sign and By-Law. New York: The MacMillan Company.

19. McNees, R.W., and Messer, C.J. (1981). Evaluating Urban Freeway Guide Signing. Report No. FHWA/TX-81/5+220-3, Washington D.C: Federal Highway Administration.

20. Transportation Research Board (1990). Safety Research for a Changing Highway Environment. Publication No. ISBN 0-309-05056-1, SR 229. Washington, DC: Transportation Research Board, National Academy Press.

21. Barr, R.A., and Eberhard, J.W. (1991). "Special Issue Preface.” Human Factors, 33(5), pp. 497-498.

22. Waller, P.F. (1991). “The Older Driver.” Human Factors, 3(5), pp. 499-505.

23. Cerrelli, E. (1989). Older Drivers, the Age Factor in Traffic Safety. Publication No. DOTHS-807-402, Washington, DC: National Highway Traffic Safety Administration.

24. Maleck, T.L. and Hummer, J.E. (1986). "Driver Age and Highway Safety." Transportation Research Record, No. 1059, Washington, DC: National Academy Press.

25. National Research Council (1988). Transportation in an Aging Society (Vols.1 and 2). Washington, DC: Transportation Safety Board, National Academy Press.

26. Ball, K., and Owsely, C. (1993). "The Useful Field of View Test: A New Technique for Evaluating Age-Related Declines in Visual Function." Journal of American Optometric Association, 64(1), pp. 71-79.

27. National Highway Traffic Safety Administration (1993). Addressing the Safety Issues Related to Younger and Older Drivers: A Report to Congress. Washington, DC: National Highway Traffic Safety Administration.

28. Lerner, N.D., Tornow, C. E., Freedman, M., Llaneras, R.E., Rabinovich, B.A., Steinberg, G.V. In press. Preliminary Investigations of Highway Design Countermeasures to Aid Drivers with Limited Experience: Literature Review and Crash Data Analysis. FHWA-RD99-XXX Washington, DC: Federal Highway Administration.

29. Decina, L.E., Gish, K.W., Staplin, L. and Kirchner, A.H. (1996). Feasibility of New Simulation Technology to Train Novice Drivers. Publication No. DTNH22-95-C- 05104, Washington, DC: National Highway Traffic Safety Administration.

30. Mourant, R.R., Rockwell, T.H., and Rackoff, N.J. (1969). “Drivers' Eye Movements and Visual Workload.” Highway Research Record, No. 292., Washington, DC: National Academy Press. 
31. Miltenburg, P.G.M. and Kuiken, M.J. (1991). "The Effect of Driving Experience on Visual Search Strategies." In: M.J. Kuiken and J.A. Groeger, (Eds.), Feedback Requirements and Performance Differences of Drivers. Haren, the Netherlands: Traffic Research Centre, University of Groningen.

32. Cain, A., and Burris, M. (1999). Investigations of the Use of Mobile Phones While Driving. Florida, USA: Center for Urban Transportation Research, University of South Florida.

33. National Highway Traffic Safety Administration (1997). Traffic Safety Facts 1996: Young Drivers. Washington, DC: National Highway Traffic Safety Administration.

34. Redelmeier, D. A. and Ticshirani, R. J. (1997). "Association between Cellular-Telephone Calls and Motor Vehicle Collisions." The New England Journal of Medicine, 336(7), 453458.

35. Violanti, J.M. (1996). "Cellular Phones and Fatal Traffic Collisions." Accident Analysis and Prevention, 30(4), pp. 519-524.

36. McKnight, J., and McKnight, A.S. (1991). The Effect of Cellular Phone Use Upon Driver Attention. Landover, MD: National Public Services Research Institute.

37. Wierwille, W.W. and Tijerina, L (1998). "Modeling the Relationship between Driver InVehicle Visual Demands and Accident Occurrence.” In: A.G. Gale, I. Brown, C. Haslegrave and S.P.

38. Olsson, S. and Burns, P.C. (2000). "Measuring Driver Visual Distraction with a Peripheral Detection Task." Obtained from August 2000 The National Highway Traffic Safety Administration Driver Distraction Internet Forum on the World Wide Web.

39. Federal Highway Administration (2000). Manual on Uniform Traffic Control Devices (MUTCD). Washington, DC: Federal Highway Administration. 